\title{
SUPERCONDUCTING MATERIALS-A REVIEW OF RECENT ADVANCES AND CURRENT PROBLEMS IN PRACTICAL MATERIALS
}

\author{
David C. Larbalestier
}

\begin{abstract}
In the four years since the last International Magnet Technology Conference, there has been a significant increase in both the breadth and scale of superconducting magnet construction. A number of advances have been pursued out of the 1 aboratory into large scale construction so that today we see large scale magnets utilizing He $I$ in free convection boiling, He I in conduit (force flow) and $\mathrm{He}$ II. Whereas four years ago filamentary $\mathrm{Nb}_{3} \mathrm{Sn}$ had only just become available in magnet conductor configurations and lengths, now it is being produced in quantity for a number of large projects. The discontinuous route to filamentary $\mathrm{Nb}_{3} \mathrm{Sn}$ has received much laboratory investigation and may soon be available for industrial scale production. Fundamental studies of $\mathrm{Nb}_{3} \mathrm{Sn}$ and other $\mathrm{A} 15$ compounds have shown that significant improvements in $\mathrm{J}_{\mathrm{C}}$ and $\mathrm{H}_{\mathrm{C} 2}$ are possible, al though not all improvements can be achieved with favorable fabrication techniques. There have also been substantial developments in $\mathrm{Nb}-\mathrm{Ti}$. Production has increased significantly and experience with large scale production runs has assisted the development of higher $J_{C}$ values in both the small diameter, fine filament conductors typical of high energy physics magnets as well as the large monolith, large filament conductors utilized for some MHD and fusion applications. Microstructural-processing studies have begun to reveal some of the crucial steps in the optimization of conductors of arbitrary size and design. At the same time it has proved possible to raise the upper critical field of $\mathrm{Nb}-\mathrm{Ti}$ by alloying, particularly with $\mathrm{Ta}$, and these alloys may find significant application in magnets of 8-12 Tesla for applications such as fusion, new higher energy accelerators and NMR. This paper reviews these and other important developments in the field of practical superconducting materials.
\end{abstract}

\section{INTRODUCTION}

To attempt a survey of recent advances and current problems in practical superconducting materials is an undertaking of considerable magnitude, given the diverse nature of the present applied superconductivity community. In order to make my task at least reasonably manageable, I have confined my comments to $\mathrm{Nb}-\mathrm{Ti}$ and $\mathrm{Nb}_{3} \mathrm{Sn}$, knowing that other materials will be discussed in a companion paper at the Workshop on the Frontiers of Technology in Superconducting Materials for Magnets[1]. There is, however, plenty to discuss for both of the above materials and the rapid increase in the scale of production seen for these materials is plainly throwing up many questions to which we do not yet have the answer.

One of the immediately obvious changes which has occurred since the last Magnet Technology Conference 4

The author is with the University of Wisconsin, Materials Science Program, Madison, WI 53706, USA. years ago has been a major increase in the size of the market for superconductors and the scale and organizational changes that have occurred in the superconducting wire industry as a result. Market surveys of all sorts have been made and there has indeed been a large increase in industry turnover and in the number and scale of the end markets for the superconductor. A characteristic of some of these new markets, for example fusion and MHD, is the fact that, however important the magnets are in the overall devices, solution of the magnet problems is by no means the most important part of the project. In other words, there has been a distinct change of emphasis to a situation where the business is now driven by the large scale industrial fabricator of the magnet instead of by the intrinsic scientific interest of the research laboratory.

At the outset of the preparation of this paper I attempted to step a little outside my usual role as a scientific investigator of the superconductor and to imagine what might be some of the questions posed by a technically competent newcomer to the business who was placing the order for a large conductor procurement for a major new magnet system. Some of the questions imagined were:

(i) Can this conductor be made reliably by several manufacturers and can it be bid realistically in open competition?

(ii) Can I scale the current density from a standard critical current density plot and expect to get about the same values in my particular design of conductor?

\section{(iii) How long a piece length can be made?}

(iv) How long do I have to wait for delivery?

(v) What prospects are there of expecting either a modest improvement in properties and/or a modest reduction in price (say of order $10 \%$ ) without technical input from my staff?

\section{(vi) Does scrap magnet wire have any value?}

There have been many cases of the single source, cost plus fee type contract response to these questions but also many cases in which conductors have been bid from one or more sources at a fixed price. Although there have been many successful procurements, there have also been sufficient failures or unexplained features of successful production to provide ample evidence that basic features of composite fabrication and property prediction lack quantitative definition. In general, however, the superconductor fabrication community has not been good at cataloguing its failures or even describing its successes in detail. Our colleagues, the magnet builders, are perhaps more forthcoming: Bruce 
Montgomery reviewed[2] a number of significant magnet failures some years ago and the tribulations of the recent TPC magnet are described by Green et al.[3] in a companion paper at this conference. This lack of discussion handicaps our efforts to understand the complex fabrication-microstructure-property relationships, many of whose quantitative detàis still remain obscure.

The plan of the present review is to select certain topics relating to recent advances or current problems. A broader perspective may be obtained from reviews in the recent ICMC conferences[4,5], the 1980 NATO Advanced Study Institute on Superconducting Materials[6] and the 1980 Applied Superconductivity Conference[7]. This author has provided two long reviews on $\mathrm{Nb}-\mathrm{Ti}[8,9]$, Suenaga two on filamentary $\mathrm{Nb}_{3} \mathrm{Sn}[10,11]$, Hillmann one on fabrication aspects of both $\mathrm{Nb}-\mathrm{Ti}$ and $\mathrm{Nb}_{3} \mathrm{Sn}[12]$, while stress effects in the A15 compounds have been reviewed by Welch[13] and Ekin[14]. In situ conductors have received several reviews[15-19], while the basic phase relationships of the A15 compounds have been reviewed by Flukiger[20].

\section{GENERAL CONSIDERATIONS}

One of the questions of increasing importance is that of standards and specifications. 'This is natural as the superconductor business leaves its research laboratory background to become an established high technology industry. One area of standards concern is that of defining critical current, another that of defining a chemical specification with permitted impurities for the raw material Nb or Nb-Ti. Successful standards will permit competent scientists and engineers, who are not themselves specialists in superconductivity, to safely specify materials and tests. However, formulation of such standards is not necessarily easy, even when the experts agree on the technical details (I believe this to be broadly the case in the case of a critical current standard), since the implications of too stringent a test may be considered financially prohibitive. Things are even more uncertain, for example, in respect of superconductor composition, since the scientific aspects of permitting greater freedom in the chemical composition are unknown. There are of course many other specifications, most quite local in application, affecting the supply and delivery of superconductor. Some of these specifications date from the very early days in superconductor manufacture and it may, therefore, be helpful periodically to ask the questions:

(i) What situations or contingencies are these specifications supposed to ensure or avoid?

(ii) Is there a good scientific or empirical base to justify the specifications?

My purpose in raising this point is to attempt to focus attention on the quantitative and predictive aspects of our knowledge, rather than the purely qualitative and generat. For example, we understand quite weil that lots of cold work and the correct heat treatment are desirable for $\mathrm{Nb}-\mathrm{Ti}$ composites. But the actual fabrication of particular composites follows a recipe which is generally secret and essentially empirical. Small changes in composite design frequently lead to considerably different properties and yields and a general concern of U.S. wire manufacturers is product variability, even given the rather stringent specification of the initial $\mathrm{Nb}-\mathrm{Ti}$.

To understand why this is so we need look no further than the connection between what the fabricator does to his composite extrusion billet and the properties that he measures before he ships it out the door. Present emphasis is on large scale production. Superconductor billets now weigh $1 / 4$ to $1 / 3$ ton, with starting diameters of 25 to $30 \mathrm{~cm}$. Annual $\mathrm{Nb}-\mathrm{Ti}$ production in the USA is about 100 tons of alloy per year and over 800 nominally identical billets of the Fermilab Energy Saver/Doubler composite (Fig. 1) have been made. Large production facilities have come into operation and many magnets been constructed.

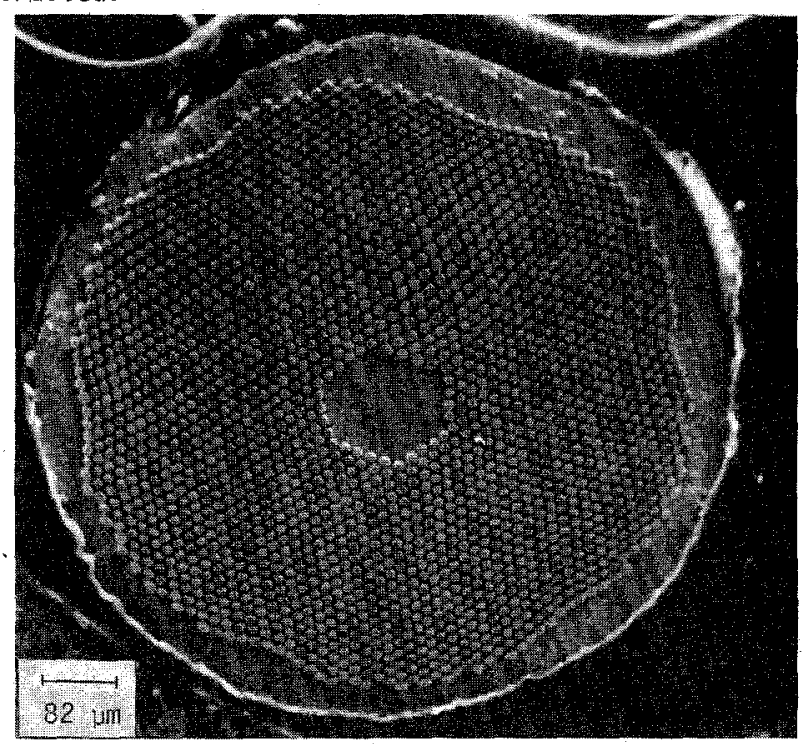

Fig. 1. Cross-section of a Fermilab composite.

If we inquire what is the mediator between the large scale fabrication equipment and the hopefully inexpensive, high quality, high current density conductor output, we shall find that this is the microstructure and its scale has not changed at all, remaining very fine in scale. The microstructure which pins the vortex lattice must be made heterogeneous on a scale comparable with that of the vortex Tattice. For both $\mathrm{Nb}-\mathrm{Ti}$ and $\mathrm{Nb}_{3} \mathrm{Sn}$, the vortex diameter is of the order $10 \mathrm{~nm}(100 \AA)$. The equilibrium separation of the vortices depends on field as $\left(\phi_{0} / B\right)^{1 / 2}$, where $\phi_{0}$ is the flux quantum, $2 \times 10^{-15} \mathrm{~Wb} / \mathrm{m}^{2}$, and $B$ is the magnetic field strength. The separation thus varies from about $40 \mathrm{~nm}$ at $2 \mathrm{~T}$ to about $15 \mathrm{~nm}$ at 10T. The fabrication process will not produce a high critical current density unless it produces a microstructure on this scale. Such microstructures can be extremely complex. Figure 2 shows a high magnification transmission electron micrograph of a small part of a very high current density filament $\left(\mathrm{J}_{\mathrm{c}} 10^{-14} \mathrm{sm}\right.$, $\left.5 T, 4.2 \mathrm{~K}=2600 \mathrm{~A} / \mathrm{mm}^{2}\right)[21]$. The microstructurat defects here are the very high density of dislocations intro- 
duced by the cold-drawing process. They have banded themselves into walls, forming a sub-band structure elongated along the drawing axis and possessing a characteristic separation of about $40 \mathrm{~nm}$. Not visible in the micrograph, but of crucial importance to the $J_{C}$, are precipitates of a normal (ie, non-superconducting) $\alpha-T i$ phase produced by special heat treatments near the final wire size. The micrograph of a $\mathrm{Nb}_{3} \mathrm{Sn}$ filament[22], in this case a transverse section normal to the drawing axis of the original $\mathrm{Nb}$, appears somewhat simpler, (Fig. 3). In this case much of the dislocation structure existing in the $\mathrm{Nb}$ is annealed away during the high temperature reaction necessary to produce the $\mathrm{Nb}_{3} \mathrm{Sn}$. So far as we know, the $\mathrm{Nb}_{3} \mathrm{Sn}$ that grows is single phase and the defect responsible for the high $J_{c}$ is the grain boundary. A crucial parameter is then the heat treatment since this controls the grain size, which should be around $100 \mathrm{~nm}$ or less if the $J_{c}$ is to be high.

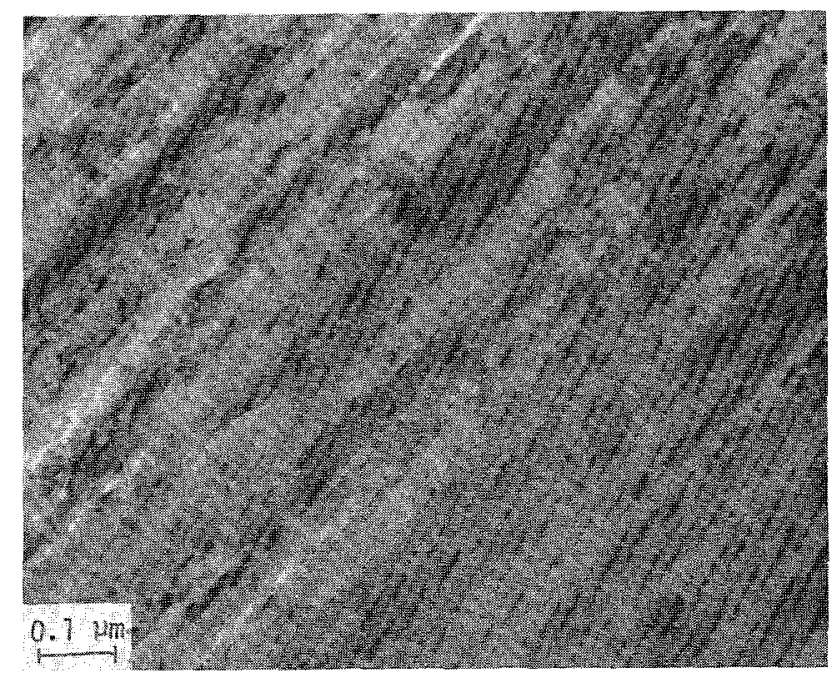

Fig. 2. Longitudinal section of a high current density $\mathrm{Nb} 50 \mathrm{w} / 0 \mathrm{Ti}$ filament[21].

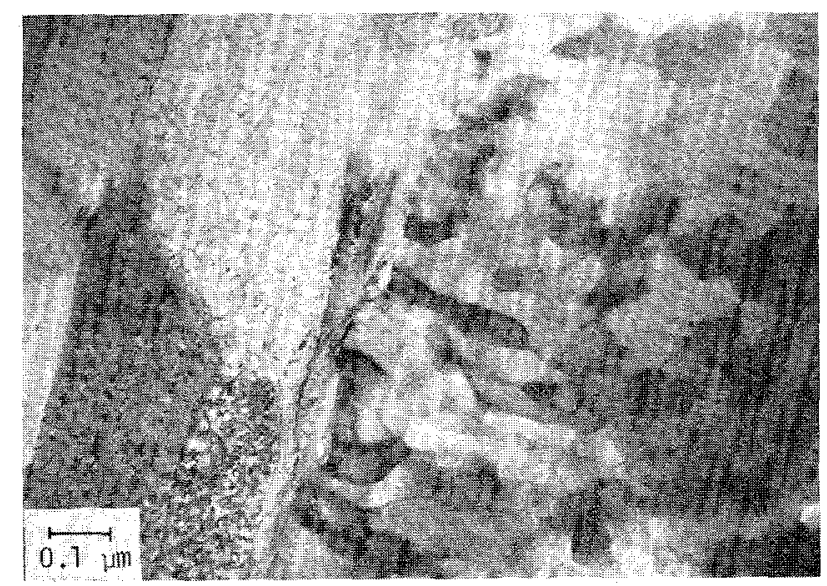

Fig. 3. Transverse section of a high current density $\mathrm{Nb} / \mathrm{Nb}_{3} \mathrm{Sn}$ filament. The $\mathrm{Nb} / \mathrm{Nb}_{3} \mathrm{Sn}$ interface runs down the middle of the micrograph[22].

This introduction of the microstructure at this stage serves to make several points: (i) The microstructure is defective on a very fine scale and contains defects of high specific energy whose scale and distribution are critically sensitive to thermal treatment.

(ii) The microstructures of high $J_{c}$ composites are of necessity inhomogeneous and because many of our common probes of the superconducting state, such as the resistive and magnetic measurement, respond preferentially to the regions of best superconducting property, we do not necessarily get a good picture of the volume distribution of the property from our measurement[23].

(iii) The fine scale of the defects, typically 10 to $100 \mathrm{~nm}$, requires sophisticated and non-routine methods of analysis, such as transmission electron microscopy.

It is perhaps for these reasons that many important production aspects of the fabrication of multifil amentary superconducting composites remain unclear. In a quantitative and predictive sense, our ignorance is still large. If we could risk a comparison with steel, we might say that although the empirical achievements of the industry have been considerable, our process control is still at the stage of, "heat to cherry red, quench into sheep dip and reheat to pale straw - and for really important deliveries it wouldn't hurt to get the phase of the moon right too".

\section{NIOBIUM-TITANIUM AND ITS ALLOYS}

Upper Critical Fields

The upper critical fields of the binary $\mathrm{Nb}-\mathrm{Ti}$ alloys are still a subject for discussion. A compilation of values from the literature is shown in Fig. 4[8,9] where, for example, $\mu_{0} \mathrm{H}_{\mathrm{c} 2}(4.2 \mathrm{~K})$ values of 12.4 Tesla have been claimed. Some of this confusion, particularly in older work, can be laid at the use of pulsed fields with short rise times and some to the use of differing definitions of $\mathrm{H}_{\mathrm{c} 2}$. A more basic problem, however, is the fundamental heterogeneity of the optimized, high $J_{C}$ superconductor, already discussed. $T_{C}$ and $H_{C 2}$ are almost invariably measured by magnetic or resistive means. In the case of $\mathrm{Nb}-\mathrm{Ti}$ and the ductile alloys the upper limit to the transition is believed to be determined by the short circuit paths of the sub-band structure and concentration gradients and other inhomogeneities are known to be present in diffusion grown layers of $\mathrm{Nb}_{3} \mathrm{Sn}[23,24,25]$.

The upper critical field is most frequently measured resistively, with some small but arbitrarily chosen current density. In cold worked alloys a broad transition of 0.5-1 Tesla width is generally found (Fig. 5) and the position of the transition can vary over a similar range depending on the exact, even if negligibly smal1, measuring current density chosen. The investigator can in addition decide to report either the first departure from superconductivity, the disappearance of the last lingering trace or the transition mid-point. An alternative definition, which has some practical validity, is to use an extrapolation function of current density and field. For $\mathrm{Nb}-\mathrm{Ti}$ and its alloys, this is just the bulk pinning 


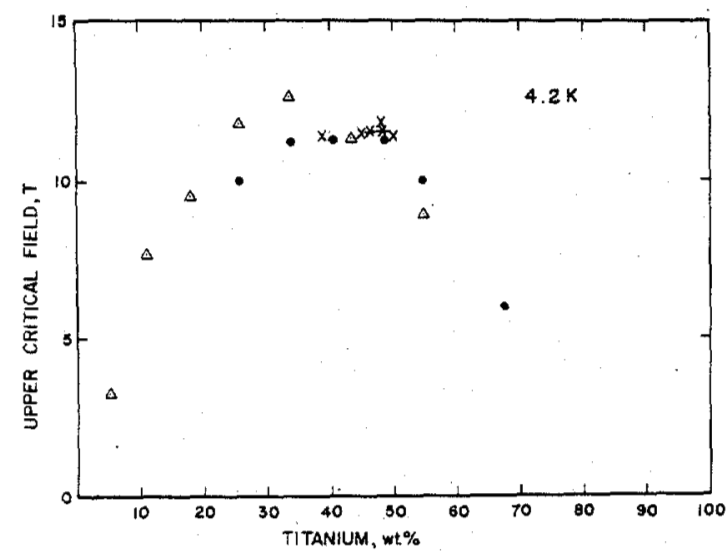

Fig. 4. Literature values of $\mu_{0} H_{c 2}(4.2 K)$ for $N b-T i[9]$.

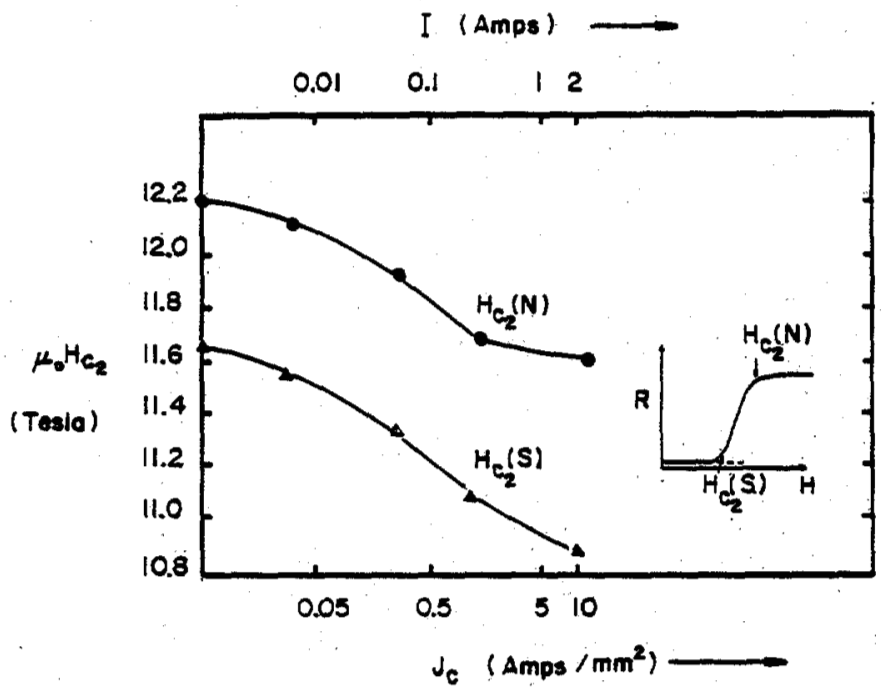

Fig. 5. Resistive $\mathrm{H}_{\mathrm{C} 2}$ transitions in cold worked $\mathrm{Nb}-\mathrm{Ti}$ alloys [28]. C?

force $F_{2}\left(=J_{C} \times B\right)[26]$, while for $\mathrm{Nb}_{3} S n$ the $\mathrm{Kramer}$ function $\left.J_{C} 1 / 2 C_{B}\right] / 4$ is more usual[27]. Anneal ing the material should, in principle, remove the heterogeneity and produce a sharp transition characteristic of the bulk material. A comparison of the $H_{c 2}$ values. obtained for $\mathrm{Nb} 46.5 \mathrm{w} / \mathrm{o} . \mathrm{Ti}$ under different conditions is shown in Table 1 . There is seen to be a spread of 0.85 Tesla or about $8 \%$ in the $\mathrm{H}_{\mathrm{C} 2}$ values. It should be noted that the linear extrapolation to zero is a very good one[26]. Our conclusion is that an unambiguous definition of $\mathrm{H}_{\mathrm{C} 2}$ is difficult and that further work is needed with techniques that measure the actual volume fraction transforming before the situation will be fully explained.

With this understanding in mind it is possible to rationalize, if not completely understand, some of the claims made for high field superconductivity in $\mathrm{Nb}-\mathrm{Ti}$ and its alloys. Two claims in particular stand out.
One in the $\mathrm{Nb}-\mathrm{Ti}-\mathrm{Zr}$ system by Alekseevski et al.[29] for a $\mu_{0} \mathrm{H}_{2}(4.2 \mathrm{~K})$ value of $13.6 \mathrm{~T}$ and one by Horiuchi et aT.[30] for 13.1T in the Nb-Ti-Ta-Zr system.

Table 1

Measured $\mu_{0} H_{c_{2}}(4.2 K)$ Values for $\mathrm{Nb} 46.5 \mathrm{w} / 0$ Ti[28]

\begin{tabular}{|lc|}
\hline $\begin{array}{l}\text { Experimental alloy as drawn } 100: 1 \text { area reduction } \\
\left(J_{c}=0.05 \mathrm{~A} / \mathrm{mm}^{2} \text {, definition as in Fig. } 5\right)\end{array}$ & $11.5 \mathrm{~T}$ \\
\hline $\begin{array}{l}\text { Experimental alloy annealed } 20 \text { mins } / 1350^{\circ} \mathrm{C} \\
\left(J_{c}=0.05 \mathrm{~A} / \mathrm{mm}^{2}, \text { by definition as in Fig. } 5\right)\end{array}$ & $11.25 \mathrm{~T}$ \\
\hline $\begin{array}{l}\text { Multifilamentary composite } \\
\left(J_{c} \times B \text { extrapolated linearly to zero) }\right.\end{array}$ & $10.65 \mathrm{~T}$ \\
\hline
\end{tabular}

Remakes of these and neighboring alloys in our laboratory $[28,31]$ produced maximum values of $\mu_{0} \mathrm{H}_{\mathrm{c} 2}(4.2 \mathrm{~K})$ of 11.0 and $11.85 \mathrm{~T}$, respectively, using even the most optimistic definition of $\mathrm{H}_{\mathrm{C} 2}$ - Using our preferred definition (the first departure from the superconducting state at $\mathrm{J}_{C}=0.05 \mathrm{~A} / \mathrm{mm}^{2}$, a value at which $H_{c 2}$ is becoming insensitive to $\mathrm{J}_{C}$, as shown in $\mathrm{Fig} .5$ ), the values are 9.7 and $11.25 T$, values which are not superior to those found in the binary $\mathrm{Nb}-\mathrm{Ti}$ system $[8,9,31]$. When we first. began to become interested in the high field properties of $\mathrm{Nb}-\mathrm{Ti}$ about 3 years ago, we were surprised at this variability and the lack of precise quantitative understanding even for pure Nb-Ti alloys. Before discussing our àlloy development work, however, it may be helpful to summarize some aspects of the theory of the upper critical field.

The theoretical framework for the understanding of the upper critical field is in principle well established. The basic equation is that of Ginzburg, Landau, Abrikosov and Gorkov (GLAG). The zero temperature predicted $\mathrm{H}_{\mathrm{c} 2}, \mu_{0} \mathrm{H}_{\mathrm{c} 2}{ }^{*}(\mathrm{O})$, is given by

$$
\mu_{0} H_{c_{2}}{ }^{*}(0)=3.11 \times 10^{3} \rho_{n}{ }^{Y} T_{c} \quad \text { (Testa) }
$$

where $\rho_{n}$ is the normal state electrical resistivity and $\gamma$ the electronic specific heat coefficient which is proportional to the density of states. For highfield, practical superconductors the constant of proportionality needs to be modified to take account of orbital paramagnetism, spin-orbit scattering, electron-phonon and electron-electron coupling effects $[32,33]$. In the binary $\mathrm{Nb}-\mathrm{Ti}$ alloys, $\mu_{0} \mathrm{H}_{\mathrm{C} 2}{ }^{*}(0)$ is not reached, due to limitations imposed by the orbital paramagnetism of the normal state; the GLAG value at $0 K$ should reach $\sim 18$ Tesla instead of the $\sim 15$ Tesla experimentally observed. A more detailed discussion of these points has been given in 2 earlier review papers $[8,9]$.

Several avenues appeared possible for alloy development aimed at increasing $\mathrm{H}_{\mathrm{c} 2}[28]$. In terms of the GLAG equation, $\rho_{n}$ is a parameter of significant structure sensitivity and the resistivity of the $\mathrm{Nb}-\mathrm{Ti}$ alloys (as for all Group IV-V alloys) is anomalously high," due to the incipient lattice instability of the body centered cubic phase[8,9]. Hafnium and vanadium are two elements which are close neighbors in the periodic table and which raise $\rho_{n}$. To summarize a fairly complex investigation somewhat incompletely, we 


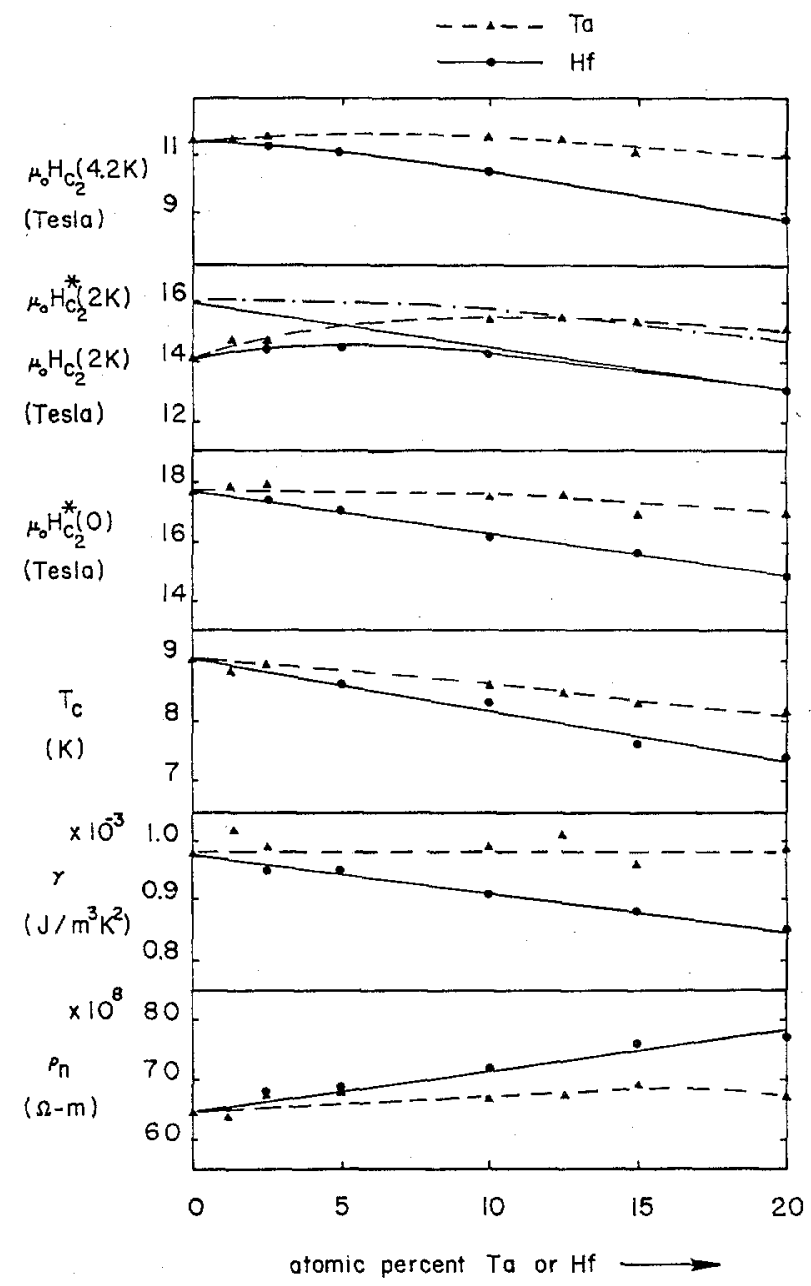

Fig. 6. The variation of $\rho_{n}, \gamma, T_{C}$, and the theoretical GLAG and experimental upper critical fjelds, $\mu_{0} H_{*}{ }^{*}$ and $\mu_{0} H_{2}$ for $\mathrm{Nb}-\mathrm{Ti}-\mathrm{Ta}$ and $\mathrm{Nb}-\mathrm{Ti}-\mathrm{Hf}$ alloys of constant electron to atom ratio (4.35) $[9,28]$.

found, however, that the resistivity increases may be outweighed by decreases in $T_{C}$ and $\gamma[9,28]$. The orbital paramagnetism of the normal state is always important and the degree of spin-orbit scattering which relieves this is therefore crucial to the development of higher upper critical fields. A comparison between $\mathrm{Nb}-\mathrm{Ti}-\mathrm{Ta}$ and Nb-Ti-Hf alloys is shown in Fig. 6. Of the parameters in the GLAG equation, $T_{C}$ is seen to decline in both cases as Hf and Ta are substituted for $\mathrm{Ti}$ and $\mathrm{Nb}$, respectively. $\gamma$ declines for substitutions of $\mathrm{Hf}$, remaining constant for substitutions of Ta. $\rho_{n}$ increases for Hf substitutions, remaining approximate$7 y$ constant for Ta substitutions. In both alloy systems, the net effect is to produce decreases in the GLAG value of $\mathrm{H}_{\mathrm{C} 2}, \mathrm{H}_{0} \mathrm{H}_{\mathrm{C} 2}{ }^{\star}(0)$. The decrease is relatively small for $\mathrm{Ta}$, somewhat larger for $\mathrm{Hf}$. What counts practical1y, however, are the experimental values. In binary $\mathrm{Nb}-\mathrm{Ti}$ alloys, there is significant paramagnetic limitation and both $\mathrm{Hf}$ and $\mathrm{Ta}$, being heavy elements, are efficient removers of the limitation through the means of spin orbit scattering[32].
The relative importance of this increases as the temperature decreases (since, at higher temperatures, the Cooper pairs are thermally disordered). Experimentaliy, no enhancement is seen in the 4.2K upper critical field of the Nb-Ti-Hf alloys, al though there is a small enhancement in the $\mathrm{Nb}-\mathrm{T} \mathrm{i}-\mathrm{Ta}$ system $(11.8 \mathrm{~T}$ vs $11.5 \mathrm{~T})$. At $2 \mathrm{~K}$, the increases become significant, particularly in the $\mathrm{Nb}-\mathrm{Ti}-\mathrm{Ta}$ system (Figs. 7 and 8 ). The effect of additions of $10-15 \%$ of $\mathrm{Ta}$ or $\mathrm{Hf}$ is to completely remove the paramagnetic 1 imitation (Fig. 6), producing an enhancement of $\mu_{0} \mathrm{H}_{\mathrm{C} 2}(2 \mathrm{~K})$ from $14.25 \mathrm{~T}$ in the best binary alloy ( $\mathrm{Nb} 46.5 \mathrm{~W} / \mathrm{O} \mathrm{Ti}$ ) to 15.5 Tesla for a wide range of alloys around $\mathrm{Nb} 25 \mathrm{~W} / \mathrm{O}$ $\mathrm{Ta} 43 \mathrm{w} / \mathrm{O} \mathrm{Ti}$. Although it is not appropriate to discuss the theoretical aspects of these results further here, we should point out that the behavior of these alloys has many features of intrinsic scientific interest that we report on elsewhere $[9,28,31]$.

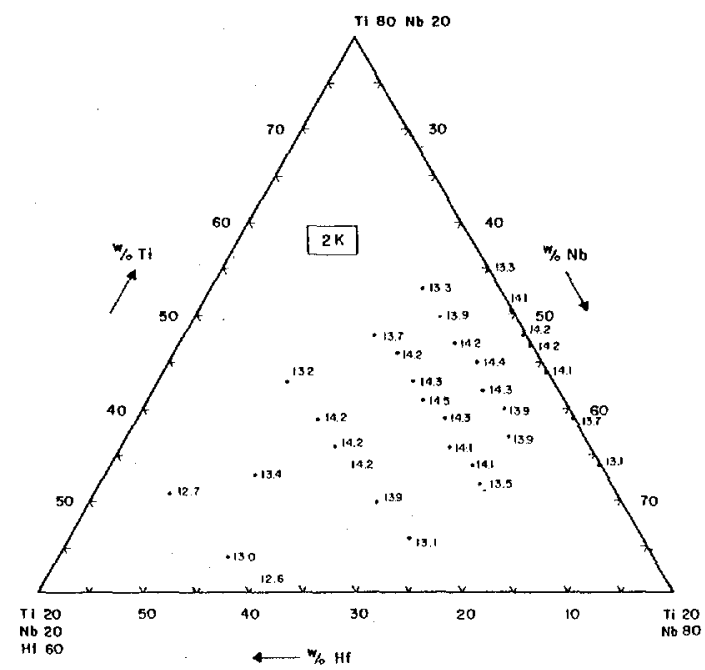

Fig. 7. Experimental upper critical fields at $2 K$ for $\mathrm{Nb}-\mathrm{Ti}-\mathrm{Hf}$ al Toys $[28,45]$.

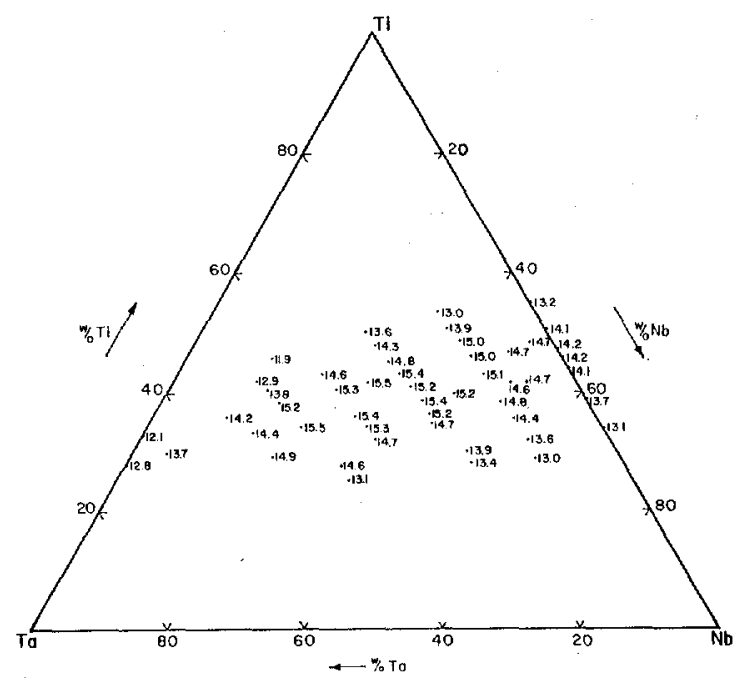

Fig. 8. Experimental upper critical fields at $2 K$ for $\mathrm{Nb}-\mathrm{Ti}-\mathrm{Ta}$ alloys $[28,45]$. 
The increases in $\mathrm{H}_{\mathrm{c} 2}$ are obtained even though the $\mathrm{T}_{\mathrm{C}}$ of the Nb-Ti-Ta alloy is lower. At high fields, however, the spin-orbit scattering process causes the $\mathrm{H}_{\mathrm{C} 2}$ vs. $\mathrm{T}$ curves of the binary and ternary alloy to cross as is shown in $\mathrm{Fig}$. 9[31]. These increases in $\mathrm{H}_{\mathrm{C} 2}$ are of considerable pràctical interest when allied with He II cooling. Industrial fabrication of the $\mathrm{Nb}$ $25 \mathrm{~W} / 0 \mathrm{Ta} 43 \mathrm{~W} / 0 \mathrm{Ti}$ alloy has taken place in the form of a Fermilab design billet which will be incorporated into the General Atomic 12 Tesla test coil[34]. The current densities attained in this alloy take the ductile alloys into at least the 12 Tesla and perhaps the 13 Tesla range, areas where $\mathrm{Nb}_{3} \mathrm{Sn}$ hitherto was the only practical alternative. We discuss the current density of this alloy in the next section.

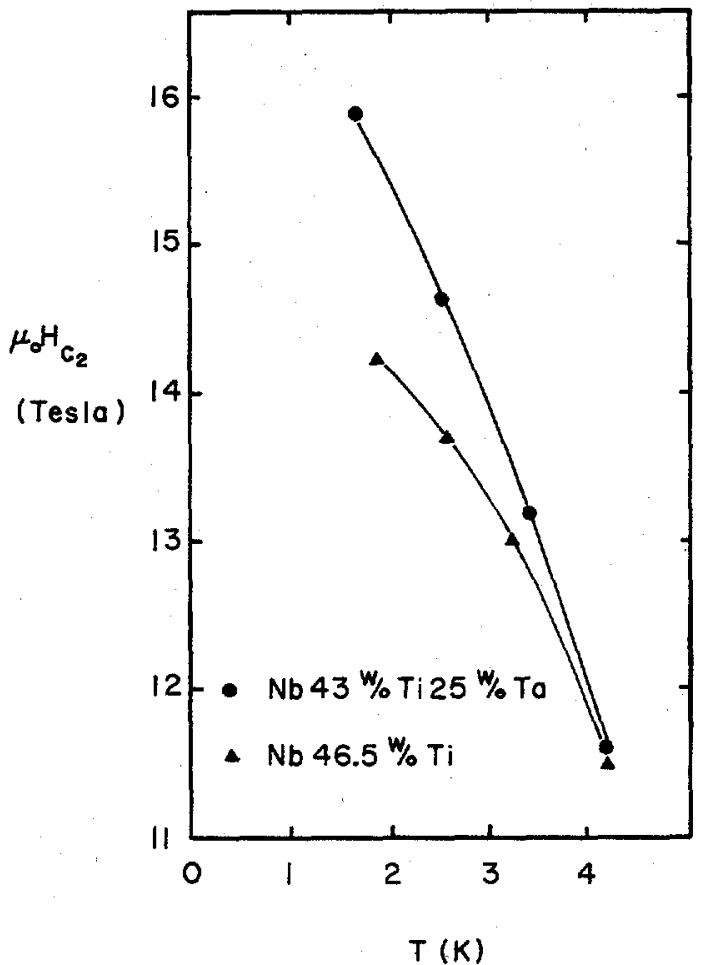

Fig. 9. Critical field versus temperature for $\mathrm{Nb} 46.5 \mathrm{~W} / \mathrm{O} \mathrm{Ti}$ and $\mathrm{Nb} 43 \mathrm{~W} / \mathrm{O} \mathrm{Ti} 25 \mathrm{~W} / \mathrm{O} \mathrm{Ta}$ [28]

\section{Critical Current Densities}

The general foundation for our understanding of the critical current density in $\mathrm{Nb}-\mathrm{Ti}$ alloys was laid down some 10 years ago in work reported by some of the superconductor manufacturers. For example, Hillmann and his co-workers[35] established the importance of $\alpha-\mathrm{Ti}$ precipitation in $\mathrm{Nb} 50 \mathrm{w} / \mathrm{O} \mathrm{Ti}$, Neal et al.[36] showed the importance of small sub-band diameter and final size heat treatment in the lower-Ti content single phase alloys such as $\mathrm{Nb} 42 \mathrm{w} / \mathrm{O} \mathrm{Ti}$, while critchiow et al.[37] showed that heat treatments performed at several times the final wire diameter were more effective than those performed at the final size. Each of these observations is still valid - yet there is still widespread secrecy over the fabrication recipe used by each manufacturer and considerable divergence in current density from one design of composite to another and even between remakes of the same design of composite.

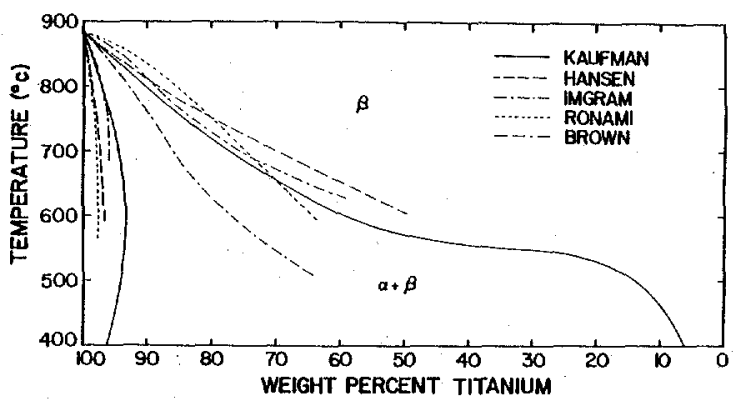

Fig. 10. The $\alpha / \beta$ phase fields in Nb-Ti[9].

An interesting detail of composite design is the question of alloy composition. Nb 50w/o Ti remains the alloy favored by Vacuumschmelze, while US manufacturers prefer the more $\mathrm{Nb}-$ rich, $\mathrm{Nb} 46.5 \mathrm{w} / \mathrm{O} \mathrm{Ti}$. As can be seen in Fig. 4, both alloys have optimal $\mathrm{H}_{\mathrm{c} 2}$ values, particularly since the $\mathrm{Nb} 50 \mathrm{w} / 0 \mathrm{Ti}$ alloys are heat treated to produce significant $\alpha-T i$ precipitation, thus making the matrix composition more $\mathrm{Nb}$ rich. The papers of Hillmann[35] have recognized this for many years but it is interesting to note that $\mathrm{Nb}$ $46.5 \mathrm{~W} / \mathrm{O} \mathrm{Ti}$ was formulated partly on the basis that fine filament, Iow AC Toss, HEP conductors required single phase alloys in order to avoid break up during drawing. The low temperature portion of the phase diagram of $\mathrm{Nb}-\mathrm{Ti}$ is shown in Fig. 10. It can be seen how flat the $\beta / \alpha+\beta$ phase boundary is in the vicinity of 45-50w/o Ti. This writer's opinion is that the exact composition of the alloy within this range is of less importance than the defect density produced by the fabrication of the alloy. Careful transmission electron microscopy of ours has shown that $\alpha-T i$ precipitation is crucjal to the development of high $\mathrm{J}_{\mathrm{C}}$ in $\mathrm{Nb} 46.5 \mathrm{w} / \mathrm{OTi}$, as in $\mathrm{Nb} 50 \mathrm{w} / \mathrm{OTi}[38,39]$. Hillmann has, however, argued that composition is very important, although without giving the processing details to support the argument[40].

When we began our studies of the critical current density in $\mathrm{Nb}-\mathrm{Ti}$ and its alloys, we were impressed by the diversity of claims made by different authors and manufacturers. The quotation, "There are three kinds of lies: Ties, damned lies and statistics" is attributed by the Oxford Dictionary of Quotations to Mark Twain through Disraeli[41]. We feel certain that a modern Mark. Twain would have felt compelled to add a fourth category "Lies, damn lies, statistics and critical current densities", to his list. Fortunately there is an ASTM committee battling presently with this problem and we send them our best wishes on their lengthy task[42]. Our comments, though facetious, are, however, meant to have a serious base. The current density can be measured precisely and it is a significant waste of valuable information to overestimate the $J_{c}$ of practical. composites by varying amounts when this information is generally the sole information avaitable to measure the effects of the complex fabrication process used to produce the conductor.

The approach that we took in our investigations was to seek out a representative selection of the 
composites being commercially produced in the world, to systematically measure their properties over the field range up to $H_{C 2}$ at $4.2 \mathrm{~K}$ and below and to use transmission electron microscopy (TEM) to characterize their microstructures. Details on. 4 of the composites thus investigated are given in Table 2, where it will be noted that there is a significant range of composition, filament size, number etc $[26,38,43]$.

Table ?

Details of the Four Commercial Nb-Ti Composites

\begin{tabular}{lccccc}
\hline & Nb $46.5 \mathrm{w} / \mathrm{oTi}$ & Nb $50.4 \mathrm{w} / \mathrm{OTi}$ & $\mathrm{Nb} 52.7 \mathrm{w} / \mathrm{OTi}$ & $\begin{array}{c}\text { Nb } 41 \mathrm{w} / \mathrm{OTi} \\
15 \mathrm{wo} / \mathrm{Ta} 8 \mathrm{w} / \mathrm{OZZ}\end{array}$ \\
\hline Wire Diameter $(\mathrm{nm})$ & 0.686 & 0.60 & 0.83 & 0.37 \\
Copper/S.C. Ratio & $1.8: 1$ & $1.2: 1$ & $1.8: 1$ & $8.86: 1$ \\
Number of Filaments & 2100 & 60 & 180 & 67 \\
Filament Size $(\mu \mathrm{m})$ & 10 & 52 & 38 & 29 \\
Sub-Band Diameter & $455 \AA$ & $400 \AA$ & $510 \AA$ & $415 \AA$ \\
$\quad$ and & + & + & + & + \\
Microstructural State & $\alpha-\mathrm{Ti}$ & $\alpha-\mathrm{Ti}$ & $\alpha-\mathrm{ri}$ & $\alpha-\mathrm{Ti}$ \\
\hline
\end{tabular}

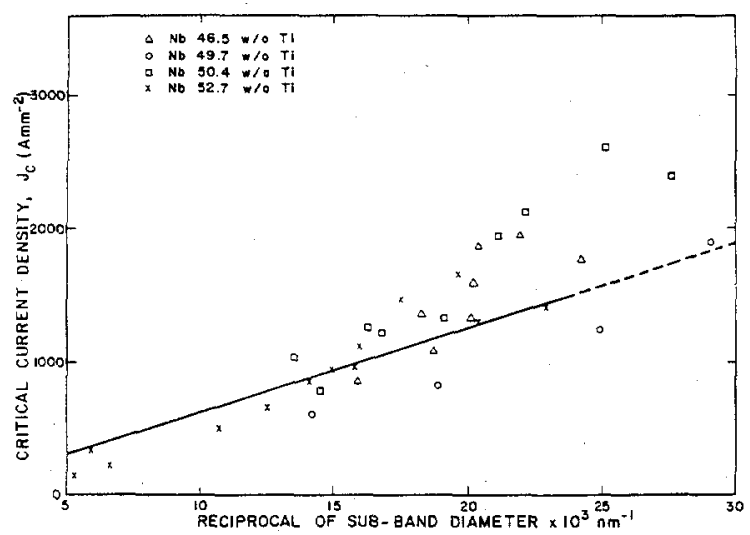

Fig. 11. Critical current density at 5T, $4.2 \mathrm{~K}$ vs. the inverse sub-band diameter[38]. The solid line is due to Neal et: a1.[36].

The TEM examinations revealed structures such as those shown in Fig. 2, where the elongated structure is an array of dislocation sub-band walls 40-50nm apart, introduced by the very large degrees of cold work[21]. Not visible in the microstructure, but of crucial importance to the development of high $\mathrm{J}_{\mathrm{c}}$ values, is an array of norinal $\alpha-T i$ precipitates (they are evident in the diffraction pattern, however). An important early investigation was that of Neal et 2].[36], who found an inverse relationship between $J_{c}$ and sub-band diameter in single phase alloys. Their maximum $\mathrm{J}_{\mathrm{C}}(5 \mathrm{~T}, 4.2 \mathrm{~K})$ value was about $1200 \mathrm{~A} / \mathrm{mm}^{2}$, a value that would be considered very low today. A plot of our data shows that the simple inverse dependence no longer holds for high $\mathrm{J}_{\mathrm{C}}$ composites, (Fig. 11[38]) since it is now the $\alpha-T i$ precipitate array which is the larger contributor to the $\mathrm{J}_{\mathrm{C}}$. However, actual data on the density and distribution of the precipitates are sparse[9] and this remains an important area of ignorance, not only because of the effect on $J_{c}$ but also because of the effect that precipitation has on initiating composite break-up.Critical current density values at $4.2 \mathrm{~K}$ and $2 \mathrm{~K}$ measured at a true $10^{-14} \Omega \mathrm{m}$ composite resistivity are given in Figs. 12 and 13 and 13 (these should therefore be excepted from Mark Twain's description). It should be emphasized that these curves are not meant to be typical or necessarily characteristic of the alloys, nor, as has been discussed earlier, is the composition necessarily the determining factor in the differences between the composites. Rather it is the overall combination of

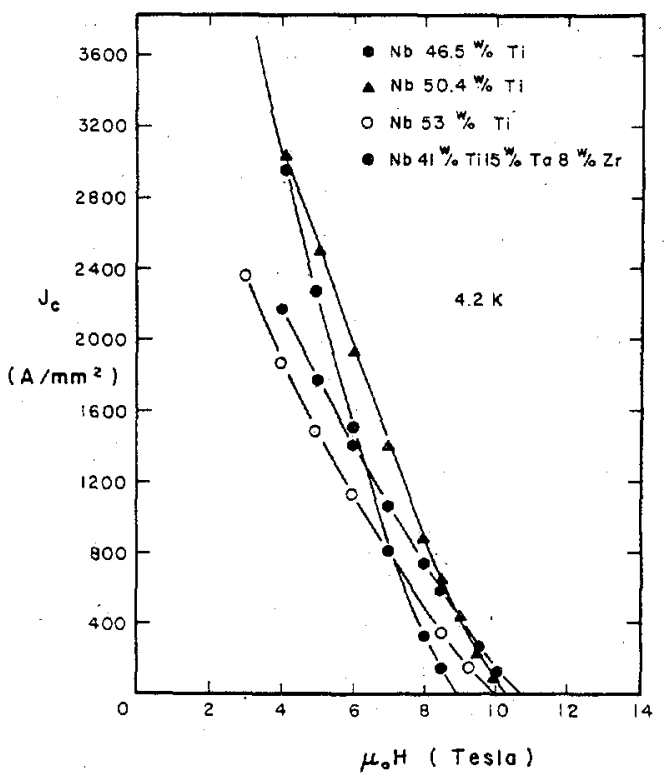

Fig. 12. Current densities of commercial composites at $4.2 K[8,26]$.

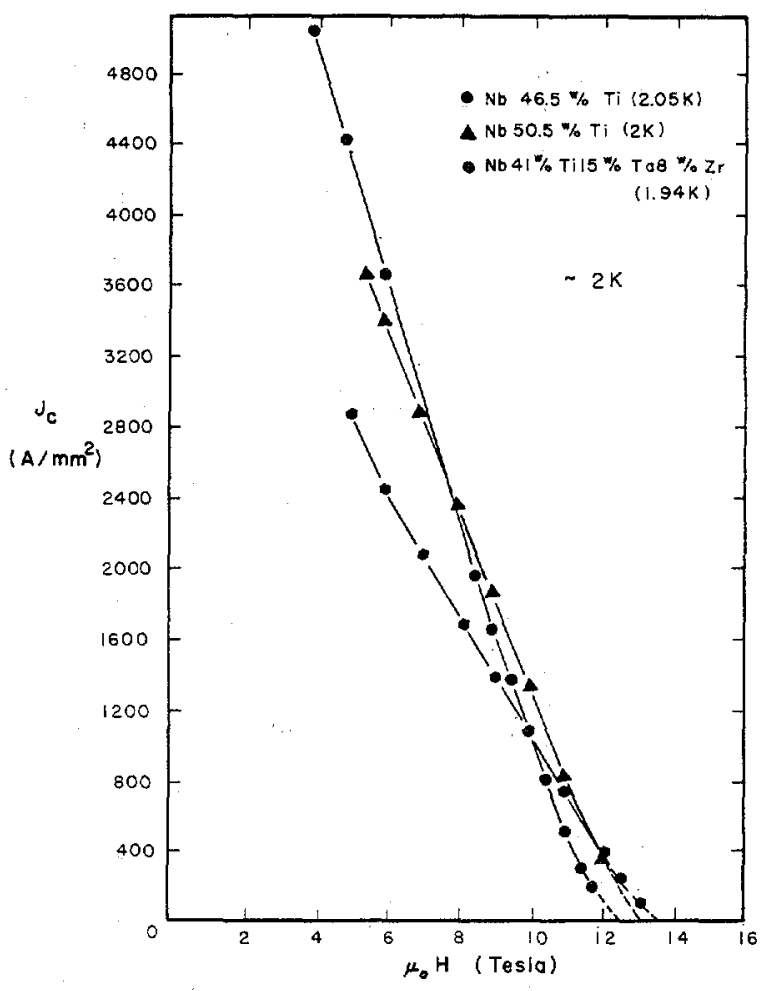

Fig. 13. Current densities of commercial composites at about $2 K[9,26]$. 
the alloy composition, the extrusion conditions, the degree of cold work and the heat treatment schedule that determines the $J_{c}$ within the $T_{c}, H_{c 2}$ envelope provided by the alloy matrix composition. Three points at least are worthy of note:

(i) There is a wide range of $J_{C}$ value at any given field (eg. $\mathrm{J}_{\mathrm{c}}(5 \mathrm{~T}, 4.2 \mathrm{~K}$ ) ranges from $\sim 1500$ to $\sim 2600 \mathrm{~A} / \mathrm{mm}^{2}, J_{c}(8 \mathrm{~T}, 4.2 \mathrm{~K})$ from $\sim 400$ to $\left.800 \mathrm{~A} / \mathrm{mm}^{2}\right)$.

( $i j)$ The $J_{C}$ at $2 K$ is substantially larger than that at $4.2 \mathrm{~K}(5 \mathrm{~T} \sim$ twice, $8 \mathrm{~T} \sim$ three times $)$.

( $i i_{i}$ ) The ternary alloy containing $\mathrm{Ta}$ and $\mathrm{Zr}$ has an extraordinarily high low field, low temperature ${ }_{\mathrm{C}}$ $\left(>6000 \mathrm{~A} / \mathrm{mm}^{2}\right.$ at $\left.2 \mathrm{~T}, 2 \mathrm{~K}\right)$. This may be attributed to the effective nature of the flux pinning $\alpha$-Ti, precipitates when $\mathrm{Zr}$ is present.

Table 3

Sub-band Diameters as a Function of Heat-Treatment and Cold-Work in a Fermilab No 46.5wt.\% Ti. FM Composite

(West and Larbalestier, [39].

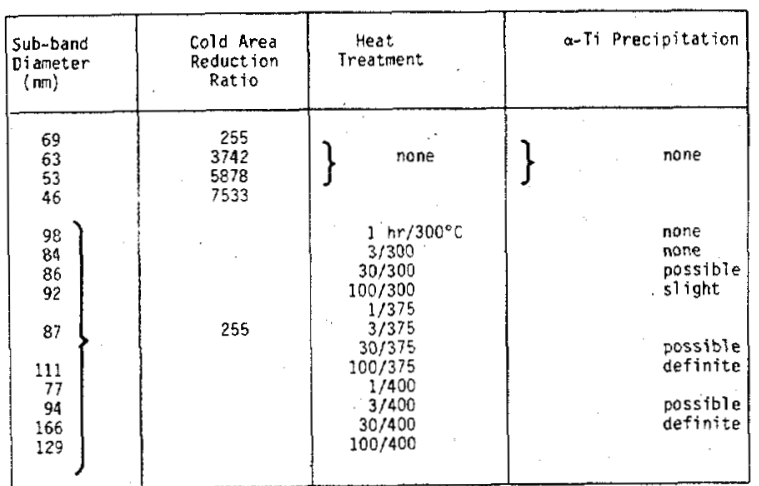

For none of the above composites were heat treatment and fabrication schedules available. In general terms, however, the schedules are well-known; a typical treatment being to extrude by $16-20: 1$ area reduction ratio at $500-550^{\circ} \mathrm{C}$, cold draw to $3-5$ times the final wire diameter and heat treat for 20-200 hours at 350 to $400^{\circ} \mathrm{C}$. More details have been given in earlier reviews by us $[8,9]$. What actually happens during the heat treatment is revealed in a recent study of ours on a Fermilab composite[39]. First, the unstable subband structure shows substantial growth and only after some considerable time does the $\alpha-T i$ precipitation process begin. (Table 3) The first of these processes tends to drive down the $\mathrm{J}_{\mathrm{C}}$, the second to drive it back up. The heat treatment takes place at a very low temperature with respect to the melting point $(\sim 0.3)$ and the diffusion processes needed to permit the $\alpha-T_{i}$ precipitation occur within the defect structure of the sub-band walls. The sub-band diameter is determined by the degree of cold work; the greater the degree of cold work, the finer is the subband diameter. The importance of cold-work is therefore its effect on sub-band diameter and on the kinetics of the sub-band growth/ $\alpha-T i$ precipitation process during heat treatment. It is here that the great complexity in the processing and optimization of $\mathrm{Nb}-\mathrm{Ti}$ lies. The small amount of published data on these points is quite insufficient to permit quantitative predictions and is the reason why composite development proceeds by trial and error optimization. Further microstructural evaluation of practical compo- sites is vital. Figure 14 exemplifies one of the complexities of microstructual examination. Two apparently similar micrastructures are shown from a final size Fermilab composite. One has a $J_{C}$ (5T, $\left.4.2 \mathrm{~K}, 10^{-14} \Omega \mathrm{m}\right)$ value of $366 \mathrm{~A} / \mathrm{mm}^{2}$, one a value of $1540 \mathrm{~A} / \mathrm{mm}^{2}$. There is a small difference in the subband diameter, 51 versus $44 \mathrm{~nm}$, but this is quite insufficient to explain the difference in $\mathrm{J}_{\mathrm{C}}$.
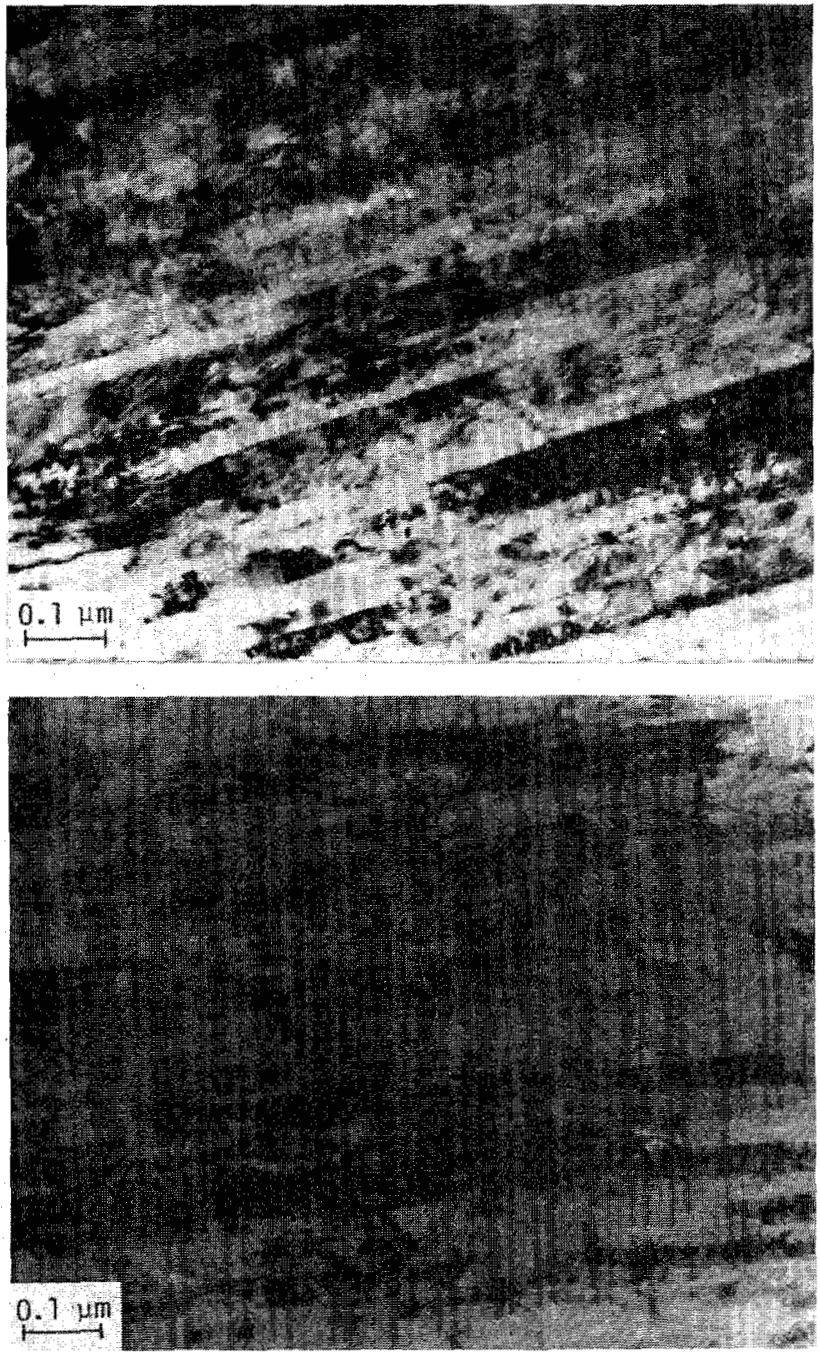

Fig. 14. Transmission electron micrographs of Fermilab composites at final size. The upper has received no heat treatment, the lower 160 hours at $375^{\circ} \mathrm{C}[27,39]$. See text for detai7s.

The crucial difference is that the higher $J_{c}$, finer sub-band material received a heat treatment of 160 hours at $375^{\circ} \mathrm{C}$ at $5-1 / 3$ times the final wire size. This heat treatment almost doubled the sub-band diameter but produced $\alpha-T i$ precipitation and the subsequent cold work in the presence of the precipitates refined the sub-band diameter to $44 \mathrm{~nm}$, below that of the sample which received no heat treatment and contained no precipitates. The $J_{C}$ of the heat treated sample was $1540 \mathrm{~A} / \mathrm{mm}^{2}$ and a subsequent heat treatment at final size $\left(3 \mathrm{hrs} / 300^{\circ} \mathrm{C}\right)$ which produced no change in 
sub-band size or presumably the $\alpha-T i$ precipitate distribution raised the $J_{C}$ further to $1670 \mathrm{~A} / \mathrm{mm}^{2}$. A fuller discussion of these and other factors affecting the $J_{C}$ may be found in a recent review[9].

\section{Scaling Behavior}

Another useful tool for assessing the quality of a superconducting composite can be the intelligent use of the scaling laws first observed by fietz and Webb[44]. These authors noted that the field dependence of the volume pinning force $F_{p}$ could be scaled by $\mathrm{H}_{\mathrm{C} 2}$, according to the empirical expression,

$$
F_{p}=J_{c} \times B=\mu_{0} H_{c}{ }^{n}(T) f(h)
$$

where $\mathrm{n}$ is an empirically determined exponent having values from about 1.7 to 2.5 for $N b-T i[9,47]$ and $f(h)$ is the shape of the pinning force curve. During the development of the $\mathrm{Nb}-\mathrm{Ti}-\mathrm{Ta}$ alloys for the 12 Tesla program[34], we made extensive use of this relationship $[26,45]$. The $\mathrm{J}_{\mathrm{c}}$ data plotted in Figs. 12 and 13 is replotted in scaling form in Figs. 15 and 16 . Figure 15 shows the magnitudes of the pinning force in the different commercial composites, where of course the maximum pinning force $F$ max varies widely depending on the degree of optimization. Note, however, that the position of $F_{\text {pmax }}$ is rather independent of composite, occurring at about $0.45 \mathrm{H} / \mathrm{H}_{\mathrm{c} 2}$ for al1. When the pinning force is itself normalized, as in Fig. 16, the curve shapes are seen to be very similar and do not depart greatly from a $h(1-h)$ dependence $\left(h=H / H_{c 2}\right)$.

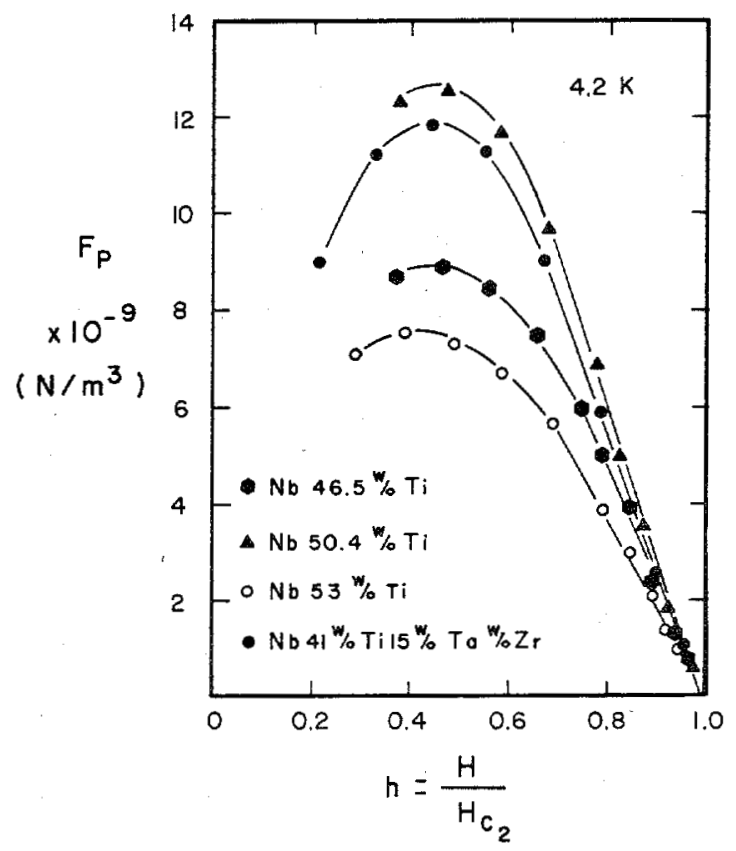

Fig. 15. Pinning force $\left(\mathrm{J}_{C} \times B\right)$ vs. reduced field at $4.2 \mathrm{~K}$ for the four Nb-Ti multifilamentary composites whose $J_{c}$ data are given in Fig. 12[8,26].
There are a number of points to be made about the scaling behavior. First, the shape of the curve is extremely sensitive to the details of the interaction between the vortex lattice (which may be amorphous, hovever, in such a strong pinning microstructure) and the microstructure. Although we do not yet know how to sum the interactions between the individual fluxoids and their pinning sites, we do know that the more efficient the pinning, the lower in reduced field $h$ will the peak in $f(h)$ occur[46]. Thus the position of $F_{\text {pmax }}$ is a significant guide to the success of optimization in a given composite and is a substantial argument for making current density measurements over at least the mid-field range where the peak in $F_{p}$ occurs (say 3 to 7 . Tesla for $\mathrm{Nb}-\mathrm{Ti}$ at $4.2 \mathrm{~K}$ ) when new composite designs are in fabrication.

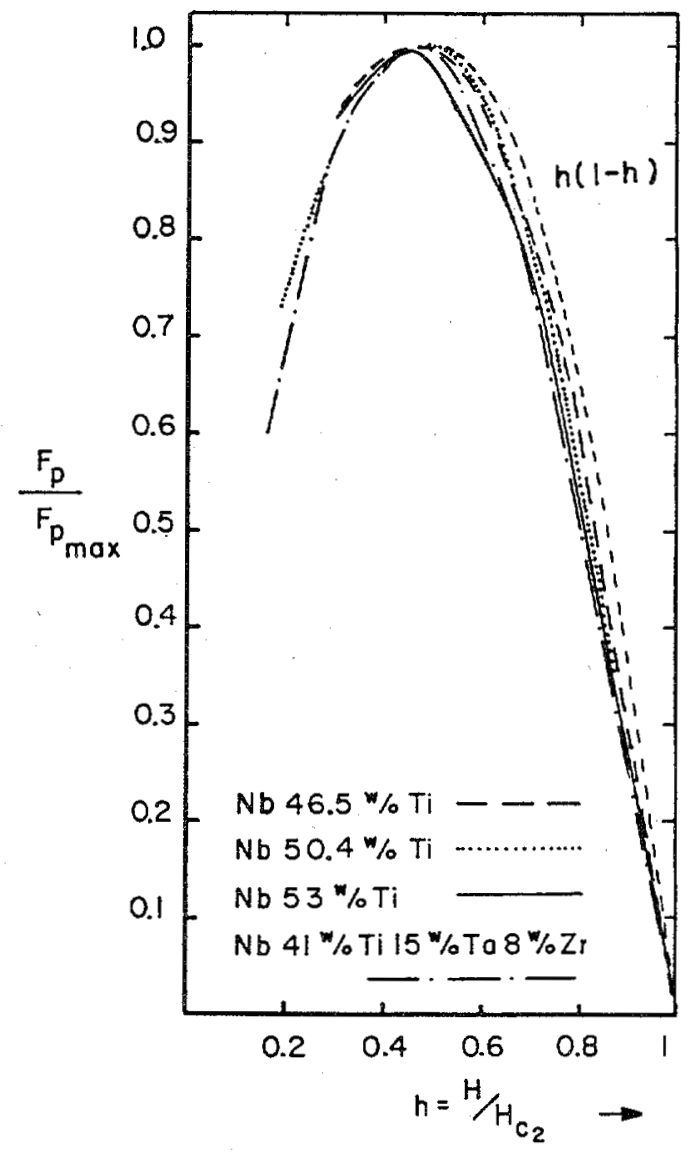

Fig. 16. Superimposed reduced pinning curves for four commercial $\mathrm{Nb}-\mathrm{Ti}$ filamentary compositès[26].

A second point is that the scaling relations can be practically very useful in saving a lot of testing. While neither the exponent in Eq. 2 nor $f(h)$ can be explicitly predicted in advance (though $n$ appears always to have a value of 2 to 2.1 for optimized conductors $[26,47]$ ), the temperature scaling of $f(h)$ is excellent [see ref. 26]. Moreover the high field shape of $f(h)$ at greater than $0.75 h$ is 1 inear to a very high degree of accuracy[26]. Both these points enable the low temperature and the high field $J_{c}$ to be 
predicted to good order.

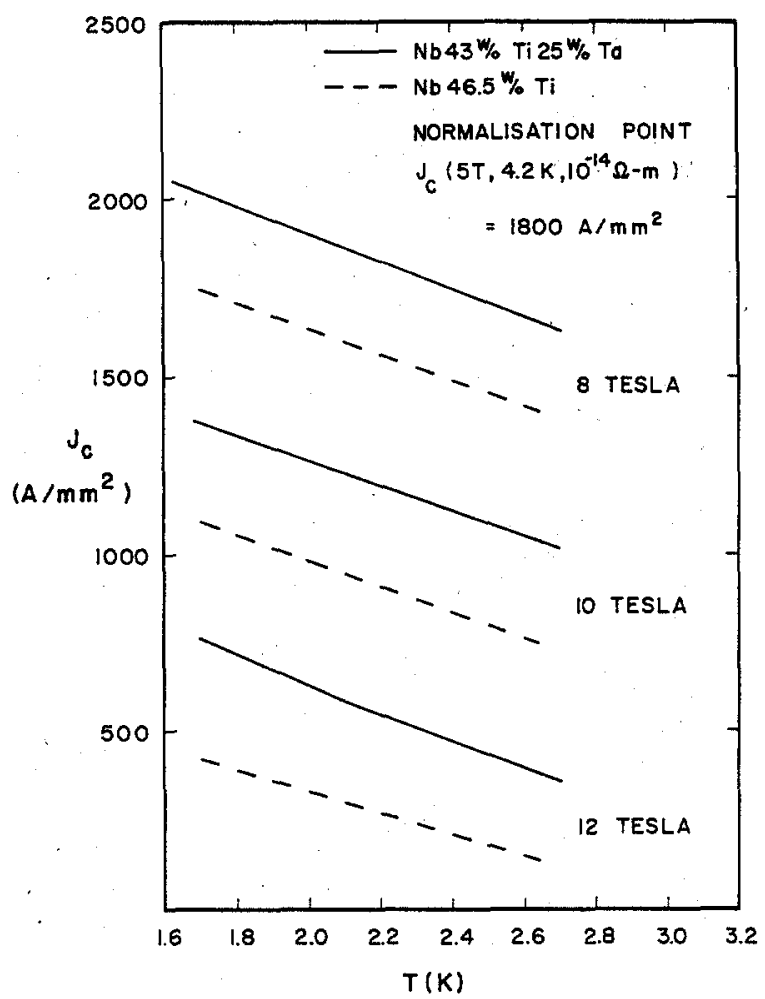

Fig. 17. Comparison of the predicted $J_{C}$ values at 8,10 and 12 Tes 7 a for $\mathrm{Nb} 46.5 \mathrm{~W} / \mathrm{O} \mathrm{Ti}$ and $\mathrm{Nb} 43 \mathrm{w} / 0 \mathrm{Ti} 25 \mathrm{w} / \mathrm{O}$ Ta composites (Courtesy D.G. Hawksworth).

Such a procedure was followed by us for the $\mathrm{Nb}$ $43 \mathrm{w} / \mathrm{O} \mathrm{Ti} 25 \mathrm{w} / 0 \mathrm{Ta}$ alloy[26]. In advance of the manufacture by MCA of a multifilament billet, we scaled the high field $J_{C}$, using Eq. 2 and our measurements of the temperature dependence of $\mathrm{H}_{\mathrm{C}}$ in our $30 \mathrm{gm}$ sample of the Nb-Ti-Ta alloy and the MCA Nb $46.5 \mathrm{w} / 0$ Ti standard product $[26,48]$. Our prediction of the 12 Tesla, $2 \mathrm{~K} \mathrm{~J}_{\mathrm{C}}$ fell within $10 \%$ of the value actually obtained by MCA[48]. Figure 17 shows that there is a considerable critical current margin for the ternary alloy and that the temperature margin of the $\mathrm{Nb}-\mathrm{Ti}-\mathrm{Ta}$ alloy over $\mathrm{Nb} 46.5 \mathrm{w} / 0 \mathrm{Ti}$ is about $0.7 \mathrm{~K}$. Further optimizations will certainly improve the current density. In fact, when the pinning force curve of the first industrial samples of the ternary alloy[48] are compared to those of $\mathrm{Nb} 46.5 \mathrm{~W} / \mathrm{oTi}[28]$, the peak in $\mathrm{F}_{\mathrm{p}}$ is seen to occur at a much higher field $(\sim 0.55 \mathrm{H}, 2$, Fig. 18). This strongly suggests that insufficient $\alpha-T i$ precipitation has occurred during heat treatment, a conclusion also supported by the relatively low $5 \mathrm{~T} \mathrm{~J}$ of this particular composite. Further developments of this alloy are discussed by segal et al.[49] in a paper at this conference.

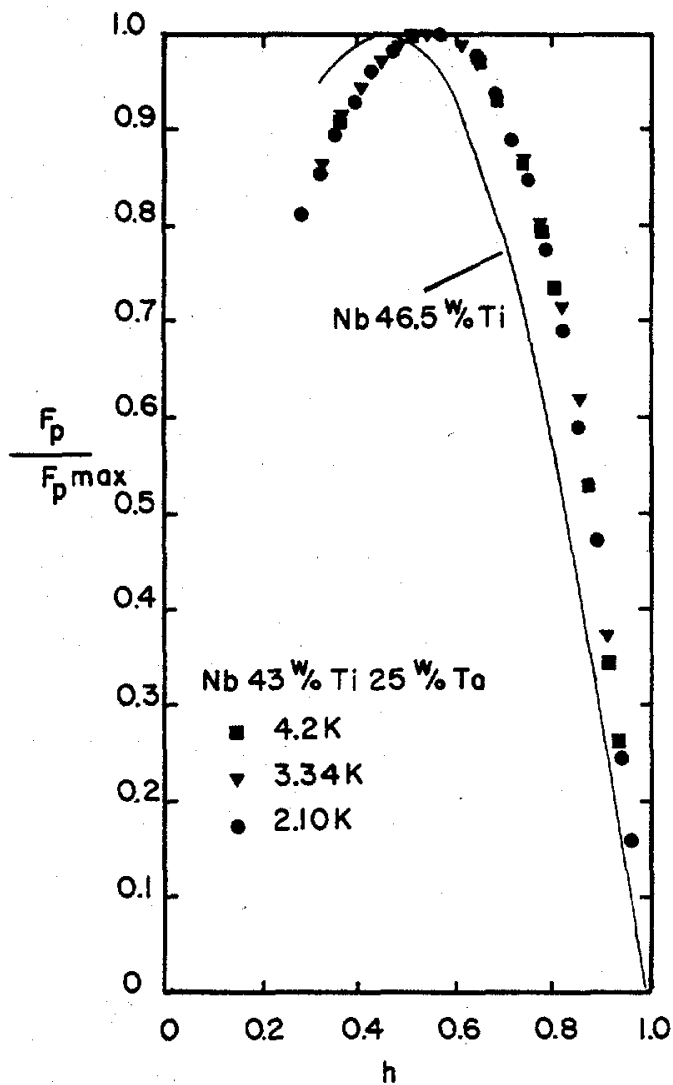

Fig. 18. Reduced pinning force curves for $\mathrm{Nb} 46.5 \mathrm{w} / \mathrm{O}$. Ti and $\mathrm{Nb} 43 \mathrm{w} / \mathrm{O} \mathrm{Ti} 25 \mathrm{w} / \mathrm{O} \mathrm{Ta}$ mut tifilamentary composites[28].

Table 4

Costs and Components for a Fermilab Energy Saver Billet (Data Courtesy of $R$. Remsbottom [50]).

$\begin{array}{lr}\text { Extrusion diameter } & 250 \mathrm{~mm} \\ \text { Final size } & 0.68 \mathrm{~mm} \\ \text { Number of filaments } & 2070 \\ \text { Filament diameter } & 8-10 \mathrm{~mm} \\ \text { Cu:Nb-Ti ratio } & 1,8: 1 \mathrm{n} \\ \text { Weight of Nb-Ti per billet } & 60 \mathrm{~kg} \\ \text { Weight of Cu tubing } & 96 \mathrm{~kg} \\ \text { Weight of Cu extrusion can } & 90 \mathrm{~kg} \\ \text { (nose cone }+ \text { tail }=36.6 \mathrm{~kg}) & 247 \mathrm{~kg} \\ \text { Total weight of extrusion } & \$ 11,880 \\ \text { Cost of Nb-Ti at } \$ 198 / \mathrm{kg} & 636 \\ \text { Cost of Cu tubing at } \$ 6.60 / \mathrm{kg} & 1,644 \\ \text { Cost of extrusion can } & \$ 14,160 \\ & -\end{array}$

Raw material cost $=\$ 57.38 / \mathrm{kg}$

Processing cost at $3 \mathrm{t} / \mathrm{ft}=9.84 \mathrm{t} / \mathrm{m}=\$ 33.86 / \mathrm{kg}$

Total cost $=\$ 57.38+\$ 33.86=\$ 91.24 / \mathrm{kg}$

\section{Fabrication and Industrial Considerations}

The reliable and economical fabrication of composites is the job of industry and there have been many considerable achievements by the industry in recent years. An interesting perspective is provided by the 
Fermilab composite, since it has been made in great quantity, by a variety of manufacturers and some reasonably firm data is available on its costs and properties. The raw material is high purity $\mathrm{Nb}$ $46.5 \mathrm{~W} / \mathrm{O} \mathrm{Ti}$ (the principal impurities are 0 and $\mathrm{Ta}$ at $1000 \mathrm{ppm} \max$, a11 others being less than $200 \mathrm{ppm}$ ) and OFHC Cu. The cost of production in 1980 was $\$ 91.25 / \mathrm{kg}$ (composed of a raw material cost of $\$ 57.40$ and a production cost to $0.68 \mathrm{~mm}$ dia, strand of $\$ 33.85$ ). The cost breakdown is shown in greater detail in Table $4[9,50]$.

The current density in the final strand has varied from time to time and manufacturer to manufacturer but is typically about $1800-2000 \mathrm{~A} / \mathrm{mm}^{2}$ (5T, 4.2K,

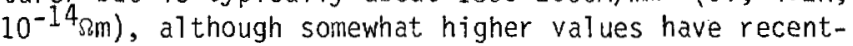
ly been obtained[51]. A magnet builder really wants ampere turns, however, so that one appropriate normalization factor is the cost per A.m. The Fermilab conductor is in fact a 23 strand compacted Rutherford cable and, including a cabling cost of $\$ 1.41$ per meter, the price per A.m for different field values are shown in Table 5 . Values are given at both 4.2 and $2 \mathrm{~K}$ so that one of the cost factors involved in a He-II system analysis may be quantified. Of course, most conductors do not have the production history of the Fermilab conductor behind them and some need to be considerably more complex. However, some idea of baseline cost is surely very useful in the scoping stage of conductor design.

Table 5

1980 Costs of Fermilab Cable per Kilo-amp-m[50].

\begin{tabular}{|c|c|c|c|c|}
\hline \multicolumn{3}{|c|}{$\begin{array}{l}\text { Single strand costs } \\
23 \text { strand cost } \\
\text { Cabling cost } \\
\text { Total cost }\end{array}$} & \multicolumn{2}{|c|}{$\begin{aligned} & 26.5 \mathrm{c} / \mathrm{m} \\
& \$ 6.09 / \mathrm{m} \\
& \$ 1.41 / \mathrm{m} \\
& \$ 7.50 / \mathrm{m}\end{aligned}$} \\
\hline \multirow[t]{2}{*}{ Field } & \multicolumn{2}{|c|}{ Current Density } & \multicolumn{2}{|c|}{ Cost per KA.m } \\
\hline & $4.2 \mathrm{~K}$ & $2 \mathrm{~K}$ & $0.2 \mathrm{~K}$ & $2 \mathrm{~K}$ \\
\hline 4 Tesla & 2200 & 3200 & $\$ 1.71$ & $\$ 0.77$ \\
\hline 5 & 1800 & 2800 & 1.38 & 0.87 \\
\hline 6 & 1400 & 2400 & 1.75 & 1.02 \\
\hline 8 & 750 & 1700 & 3.26 & 1.44 \\
\hline 10 & 150 & 1050 & 16.32 & 2.33 \\
\hline 12 & --- & 400 &.-- & 6.12 \\
\hline
\end{tabular}

The above values are based on a nominal critical current of $5500 \mathrm{~A}$ at $5 \mathrm{~T}$ and $4.2 \mathrm{~K}$, corresponding to a $u_{\mathrm{c}}\left(10^{-14} \mathrm{am}\right)$ value of $3800 \mathrm{~A} / \mathrm{mm}^{2}$.

A recent introduction to the U.S. market by wah Chang has been $\mathrm{Nb}$ derived from pyrochlore ore. The principal feature of the use of this ore is that the $\mathrm{Nb}$ is likely to have a higher residual $\mathrm{Ta}$ content than that made from columbite ore, perhaps leading to residual $\mathrm{Ta}$ levels of as much as $5000 \mathrm{ppm}$ in $\mathrm{Nb}$ and $\mathrm{Nb}-\mathrm{Ti}[52]$. Experiments on model alloys[9,53] of $\mathrm{Nb}-\mathrm{Ti}$ suggest that there is 1 ittle cause for concern, though the whole question of small impurity levels (such as $\mathrm{Fe}$ ) is really not well understood. Significant economic gains have been predicted from the use of pyrochlore $\mathrm{Nb}[53]$ and their current introduction is being monitored to see whether these predictions turn out to be true.
A final point to be considered in the fabrication of $\mathrm{Nb}-\mathrm{Ti}$ conductors is the question of conductor assembly. Large magnets run at currents of one to tens of thousands of amperes. High current densities require large area reductions $\left(\sim 10^{4}: 1\right)$, while initial extrusions are presently limited to about $30 \mathrm{~cm}$ in diameter. Although there have been examples of 1 arge, monolithic conductors (eg. MFTF), the general tendency is to assembly by cabling or braiding, as in the Fermilab cable or Brookhaven Isabelle braid. The question of changes in current density which occur during the assembly of optimized strands can still be extremely vexing. Optimized strands require $\alpha-T i$ precipitates but subsequent over-working of such strands can produce excessive breakage or reduction in current density. This is an important area where little understanding yet exists but whose practical importance is considerable.

An alternative approach to conductor build up has recently been developed at Airco for the Elmo Bumpy Torus and Tore-II conductors[54]. Individual strands of a standard conductor, such as the Brookhaven Isabelle design, are assembled together near their final size and continuously wrapped with a Cu strip which is automatically welded to form a continuous sheath. A final drawing and heat treatment produces a high current conductor having the degree of cold work belonging to a small diameter conductor (Fig. 19).

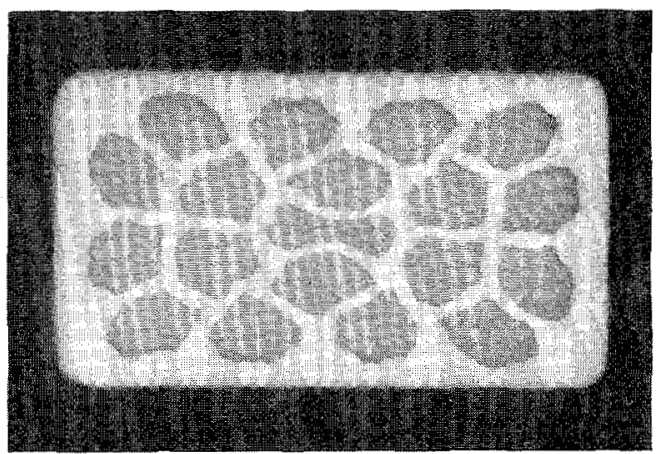

Fig. 19. Compacted monolith conductor for EBT made of 19 Brookhaven Isabelle design strands (Courtesy of S.0. Hong).

\section{NIOBIUM-TIN}

The basic conductor design for $\mathrm{Nb}_{3} \mathrm{Sn}$ is more complex than for $\mathrm{Nb}-\mathrm{Ti}$ because there are now four components in the composite, the tin supply, the $\mathrm{Nb}$, the diffusion barrier and the high purity stabilizing $\mathrm{Cu}$. The intrinsic brittleness of $\mathrm{Nb}_{3} \mathrm{Sn}$ requires reaction at final size and diffusion rates are so slow that filaments of much less than 10 um are needed in order to keep reaction times reasonable. The large number of components in the composite and the smal 1 filament size tends to exacerbate the problems of coprocessing; filament sausaging and irregular filament shape are constant problems to be avoided. 
If bronze is used for the tin supply, many anneals are needed to avoid cracking the bronze and some reaction to $\mathrm{Nb}_{3} \mathrm{Sn}$ occurs at each anneal, perhaps posing problems if filaments of less than $5 \mu m$ are needed. For the present, the only composites of practical importance are the conventional bronze route composites containing $\mathrm{Nb}$ embedded in a bronze matrix, generally $\mathrm{Cu} 13 \mathrm{w} / 0 \mathrm{Sn}$. In essence, their design remains essentially similar to the first prototype magnet conductors introduced at the 1974 Applied Superconductivity Conference[55,56]. Many different variants of composite designs have since been produced and evaluated.

Although the capability for the production of $\mathrm{Nb}_{3} \mathrm{Sn}$ composites is in principle well-established there are still large uncertainties regarding the intrinsic properties of $f i l$ amentary (FM) $\mathrm{Nb}_{3} \mathrm{Sn}$ composites. Particular problems are the fact that the diffusion 1 ayers of $\mathrm{Nb}_{3} \mathrm{Sn}$.generally have a composition gradient across them, leading to inhomogeneous. superconducting properties[23-25], and that the properties of $\mathrm{Nb}_{3} \mathrm{Sn}$ are very. sensitive to stress and thus show marked effects, which may be very variable on a local scale, resulting from the compression exerted by the surrounding bronze[13,14].

For these and other reasons there is as yet little general agreement on what the basic envelope of properties to be obtained from a $\mathrm{FM} \mathrm{N}_{3} \mathrm{Sn}$ composite should be and why present composites show such variable properties. An index of this situation, which particularly strikes the present writer, is the range of bronze to $\mathrm{Nb}$ ratios chosen by different manufacturers, values ranging from 4.6 to $2: 1$ being manufactured[57-59].

In order to restrict these comments to those of reasonable extent, the principle discussion will bear on bronze route $\mathrm{FM} \mathrm{N} \mathrm{Nb}_{3} \mathrm{Sn}$. A wider perspective can be obtained from a number of the more general reviews; already noted in the introduction[10-20].

\section{Basic Properties and Their characterization}

A logical place to begin is in the selection of starting bronze and $\mathrm{Nb}$ needed to form the $\mathrm{Nb}_{3} \mathrm{Sn}$. knowledge of the required qualities and purities of these constituents is of course of considerable economic importance yet there are still important areas of disagreement. There is, at least in the USA, no general agreement yet on whether the $13 \mathrm{w} / 0$ bronze should be air or vacuum cast and on what the tolerance for oxygen is. Experience has been variable. The successful AERE bronzes were ali air melted[55,59,60] as is the bronze for the LCP conductor [61] but Livermore has favoured vacuum casting as producing a more ductile bronze[62]. The oxygen solubility in pure $\mathrm{Cu}$ is extremely low ( $110 \mathrm{ppm}$ at $\left.700^{\circ} \mathrm{C}\right)[63]$, (although it is very mobile) but there is much unpubtished "folk-lore" that oxygen solubility is higher in bronze and exerts significantly deleterious effects on both the fabricability and the final properties of the composite. High purity $\mathrm{Sn}$ and $\mathrm{Cu}$ are generally used for the bronze but again there appears to be little agreement on the required purity or the deleterious impurities which are being guarded against in selecting high purity starting elements. There are fewer concerns about the purity of the $\mathrm{Nb}$, since the electron beam melting process is inherently capable of purifying down to very low levels, but even here the requirements of co-processing may require special selection of the $\mathrm{Nb}$.

The selection of input purities must be judged both against the test of fabricability through multiple extrusion (generally required because of the small size and large filament number), wire drawing, multiple annealing and the properties obtained after the composite is reacted at final size.

Characterization of the final size properties is not necessarily straightforward, however.

Chemical analysis of thin layers of 1-2um or less is not at all routine since, although most

laboratories have access to standard electron probe microanalyzers and they are frequently used to probe $\mathrm{Nb}_{3} \mathrm{Sn}$ layers, their limit of resolution lies between 1 and 2 um. Recourse must therefore be made to more exotic techniques such as Auger electron spectroscopy (AES). Recent work in our 1aboratory[24,25] has shown that, with carefut correction procedures, the composition and impurity profile can be obtained on a scale of about $0.1 \mathrm{um}$ (Fig. 20). These studies have produced at least two interesting points, the first being that the $S n$ concentration profile is relatively fiat, thus ensuring good superconducting properties over most of the layer. Most of the required concentration gradient thus appears to occur close to the $\mathrm{Nb} / \mathrm{Nb}_{3} \mathrm{Sn}$ interface.

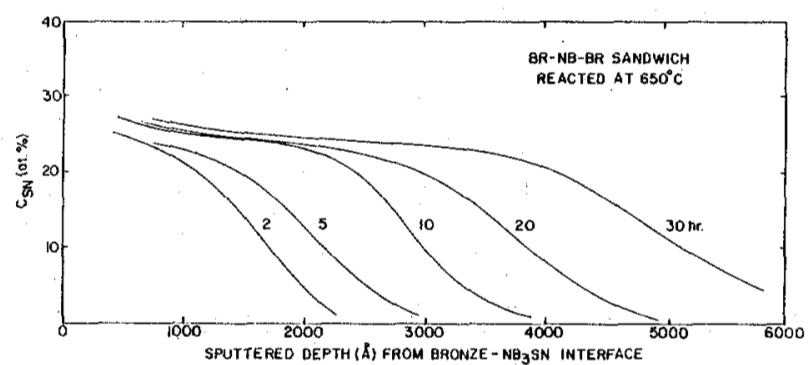

Fig. 20. Auger electron spectroscopy sputter profiles for the Sn peak obtained on diffusion grown $\mathrm{Nb}_{3} \mathrm{Sn}$ layers. The zero sputtered depth is the bronze-Nb3Sn interface. The Sn concentration drops to zero as the $\mathrm{Nb}$ core is reached. (Courtesy of D.B. Smathers)

The second point relates to the reduced properties of thin layers. Thin layers (<200nm) are seen to be high in 0 and possibly $c$ too, reducing the Sn content below stoichiometry and depressing the superconducting properties[25]. This is clear evidence for the deleterious effect of 0 on $\mathrm{Nb}_{3} \mathrm{Sn}$ properties, though it is unclear whether the 0 source originated in the bronze or was derived from the 0 originally adsorbed on the surface of the $\mathrm{Nb}$ rods.

A detailed analysis of the capabilities of magnetization measurements for revealing the structure of thin Tayers of $\mathrm{Nb}_{3} \mathrm{Sn}$ has been presented by Evetts 
et a1.[23] and their discussion of the capabilities and limitations of the basic electrical and magnetic characterization experiments is invaluable for workers seeking to use such techniques to reveal basic information about thin layers[23].

\section{Transition Temperatures and Upper Critical Fields}

Due to the surrounding matrix and the axial compressive strain imposed on the $\mathrm{Nb}_{3} \mathrm{Sn}$, there exists a significant depression of both the $T_{C}$ and $H_{C 2}$ of FM $\mathrm{Nb}_{3} \mathrm{Sn}[10,13]$. Since the depression depends on such factors as the bronze to $\mathrm{Nb}$ ratio and the yield strength (and residual composition) of the bronze, it is necessary to remove the bronze in order to be able to assess the fundamental quality of the $\mathrm{Nb}_{3} \mathrm{Sn}$.

The $T_{C}$ depression is well established to be parabolic in the axial strain[13], reaching a maximum of about $1.2 \mathrm{~K}$ for large bronze to $\mathrm{Nb}$ ratios. Practical ratios $(2.5-4.5: 1)$ reduce $T_{C}$ by about $0.5 \mathrm{~K}$. When the bronze is etched off, maximum $T_{C}$ values reach about $18 \mathrm{~K}, 0.1-0.3 \mathrm{~K}$ below the maximum recorded for pure $\mathrm{Nb}_{3} \mathrm{Sn}$. This may be due to $\mathrm{Cu}$ incorporation in the layer, residual inhomogeneities or strains or other presently unknown factors.

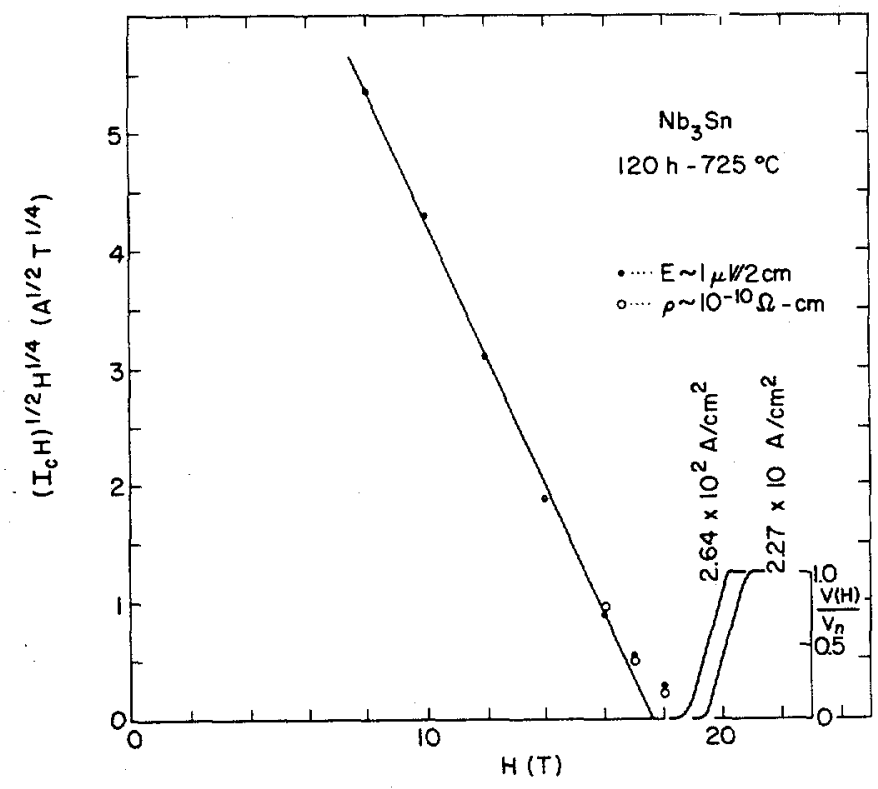

Fig. 21. A plot of $J_{C}^{1 / 2} H^{1 / 4}$ vs. $H$ for a monofilamentary $\mathrm{Nb}_{3} \mathrm{Sn}$ wire which was heat treated at $725^{\circ} \mathrm{C}$ for $120 \mathrm{~h}$, indicating the extrapolated $\mathrm{H}_{\mathrm{C} 2}$ and the low current density $\mathrm{H}_{\mathrm{C}}[64]$.

Although there is good agreement on the $T_{C}$ values to be expected, the question of $\mathrm{H}_{\mathrm{c} 2}$ is more unclear. Few workers have made measurements at other than $4.2 \mathrm{~K}$ and even fewer have had access to fields greater than $\mu_{0} \mathrm{H}_{\mathrm{C} 2}(4.2 \mathrm{~K})$. An extrapolation function is, therefore, needed in order to derive the $\mathrm{H}_{\mathrm{c} 2}$ from lower field $\mathrm{J}_{\mathrm{c}}$ measurements. This question has been extensively discussed by Suenaga and Welch[10,64]. The kramer function $J_{C}^{1 / 2} B / 4$ is found to be a linear function of the $\mathrm{J}_{\mathrm{C}}$ over much of the field range ( 10 to $\left.18 \mathrm{~T}\right)$ but increasing divergences are noted thereafter, high field tails existing to $22 \mathrm{~T}$ or higher (Fig. 21). If the pinning center density is higher than is narmal for $\mathrm{FM} \mathrm{Nb}_{3} \mathrm{Sn}$ (eg. in irradiated material or very small filament in situ conductors), a $\left(1-a_{0} \sqrt{\rho}\right)$ multiplying correction factor must be used to linearize the $\mathrm{J}_{c}$ plot (where $\mathrm{a}_{0}$ is the fluxoid separation and $p$ the density of flux pinning sites.) However, even for field ranges where this scaling relation works wel1, the magnitudes of the scaling parameters are shown to be incompatible with some of the basic physical properties of $\mathrm{Nb}_{3} \mathrm{Sn}$. The physical basis of the Kramer model as applied to $\mathrm{Nb}_{3} \mathrm{Sn}$ thus appears doubtful although it may be useful as an empirical tool[64]. To the uncertainty in $\mathrm{H}_{\mathrm{c}}$ ? generated by the use of an extrapolation function, we may add the additional uncertainties of the possibilty of a low temperature cubic-tetragonal phase transformation and a general lack of measurements of $\gamma$ and $\rho_{n}$, data which are needed to fit the behavior of $\mathrm{Nb}_{3} \mathrm{Sn}$ to the basic GLAG and WHH theories

(Eq. 1) $[32,33]$. Measurements of $\rho_{n}$ in $\mathrm{FM} \mathrm{Nb}_{3} \mathrm{Sn}$ are really not feasible, due to the irregularity of the cross-section (Fig. 22)[66] and the presence of an unreacted $\mathrm{Nb}$ core and $\gamma$ can therefore not be deconvoluted from the slope $\left(\mathrm{dH}_{\mathrm{C} 2} / \mathrm{dT}\right)$ at $\mathrm{T}_{\mathrm{C}}$, which is proportional to $\rho_{n} \gamma$.

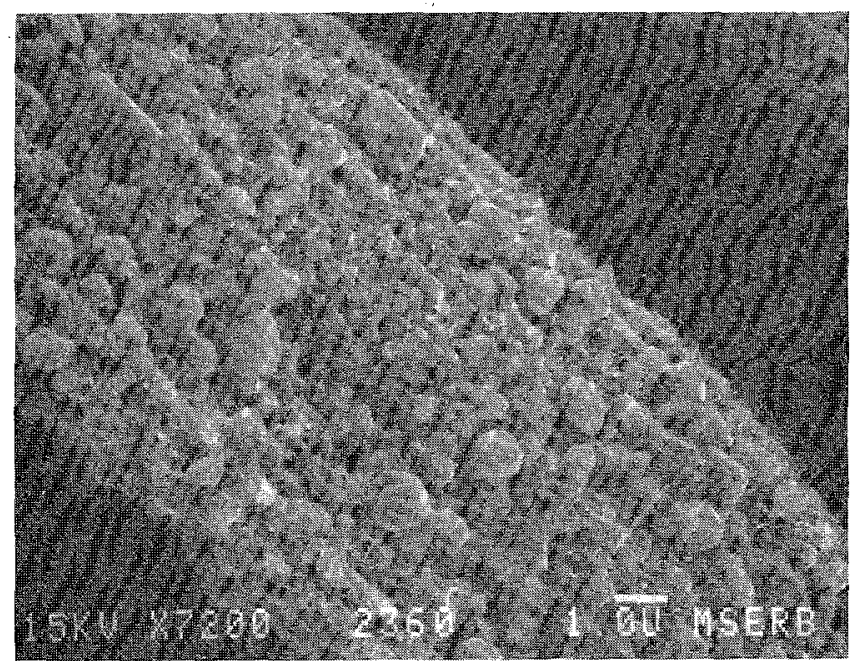

Fig. 22. Scanning electron micrograph of a single filament from a multifilament $\mathrm{Nb}_{3} \mathrm{Sn}$ composite. The 7 ayer was reacted to completion at $780^{\circ} \mathrm{C}$ for $168 \mathrm{hrs}$.

Recent work on electron beam evaporated films $[33,66]$ and bulk samples[20,57] has indicated that there should be considerable scope for improvement in the upper critical field. Figure 23 is taken from the work of orlando et al.[66] on thin films deposited on sapphire substrates $\left(\rho_{n}\right.$ and $\gamma$ can then be determined and the properties compared to 
theory[33]). Peak $\mu_{0} \mathrm{H}_{\mathrm{C} 2}$ values are seen to attain $29 \mathrm{~T}$ at $0 \mathrm{~K}$ or $\sim 25 \mathrm{~T}$ at $4.2 \mathrm{~K}$, for a $T_{C}$ value, however, of about $16 \mathrm{~K}$ and a relatively high $\rho_{n}$ of $\sim 25 \mathrm{\mu} \Omega \mathrm{cm}$. These values are some 3 to 5 Tesla higher than those commonly observed for $\mathrm{FM} \mathrm{Nb}_{3} \mathrm{Sn}$.

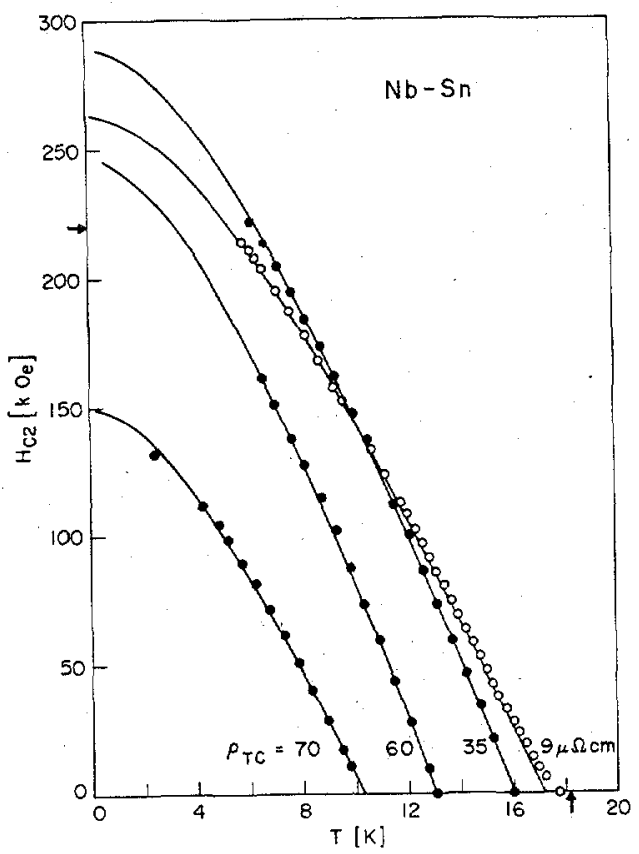

Fig. 23. Critical fields of Nb-Sn with different normal state resistivities $\rho T_{C}{ }^{\circ}$. As the resistivity $\rho_{T C}$ increases, $T_{C}$ decreases but $H_{c 2}$ goes through a $\operatorname{maximum}[66]$.

A possible explanation for the depression of $\mathrm{H}_{\mathrm{C} 2}$ and the large stress sensitivity of $\mathrm{H}_{\mathrm{C} 2}$ has been advanced in a number of recent publications[68-72]. The principal proposal is that the unstressed composite leaves the $\mathrm{Nb}_{3} \mathrm{Sn}$ in substantially the tetragonal state, tensile strain then causing growth of the higher $\mathrm{H}_{\mathrm{C} 2}$ cubic phase $[67,69]$. A number of groups are active in this area and conclusive evidence should soon be available to support or deny this explanation.

The Titerature on 3rd element additions to $\mathrm{Nb}_{3} \mathrm{Sn}$ is rather extensive and we refer to Suenaga for recent reviews[8,9]. Ta, $\mathrm{Zr}, \mathrm{Hf}$ and $\mathrm{Ti}$ can increase $\mathrm{H}_{\mathrm{c} 2}$ (as judged by critical current extrapolations) towards the 25T leve1[74]. At present the reasons for the increases are not clear; they inay reflect either an intrinsic increase in $\mathrm{H}_{\mathrm{c}}$ due to changes in the properties which go into Eq. 1 or a modification of the cubic/tetragonal phase balance so as to produce more of the cubic high $H_{c 2}$ phase[69,71,72].

\section{Critical Current Density}

Critical current densities in $\mathrm{FM} \mathrm{Nb_{3 }} S n$ are found to vary quite widely and particularly above $12 \mathrm{~T}$, the $J_{C}$ is found to fall off rather rapidly. When the pinning force of presently optimized $\mathrm{FM} \mathrm{Nb}_{3} \mathrm{Sn}$ is compared to that of $\mathrm{Nb}-\mathrm{Ti}(\mathrm{Fig.24})$, the $\mathrm{Nb}_{3} \mathrm{Sn}$ is seen to be rather under-optimized at high fields[57]. This probably reflects the fact that significant pinning is produced only by grain boundaries. The differing shapes of the two curves does draw attention to the considerable gains that could be made if $\mathrm{Nb}_{3} \mathrm{Sn}$ could be optimized to the same extent as Nb-Ti.

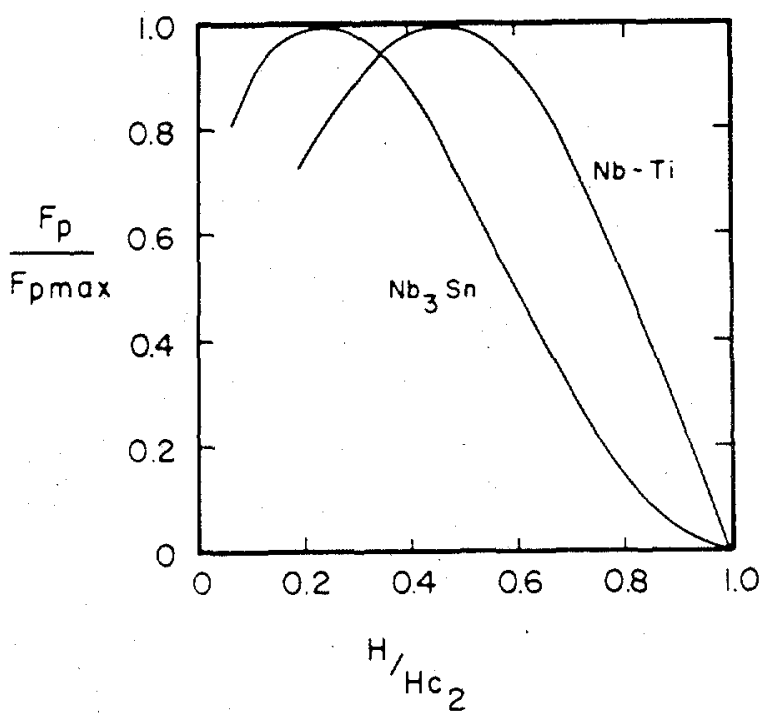

Fig. 24. Pinning force curves for optimized FM $\mathrm{Nb}_{3} \mathrm{Sn}$ and $\mathrm{NbT} \mathrm{i}$ conductors [57].

From a fundamental point of view, the $J_{c}$ in the layer is the crucial quantity but the large number of filaments, their small size and irregular shape makes the determination of the cross-sectional area difficult. Practically, it appears more reasonable to normalize the critical current to the original bronze $+\mathrm{Nb}$ package needed to make the $\mathrm{Nb}_{3} \mathrm{Sn}$ and this is almost invariably the method used today. This will however obscure changes in layer $\mathrm{J}_{\mathrm{C}}$ : for example it is perfectly feasible for the $J_{c}$ in the layer to decline as the reaction proceeds, while the overall $\mathrm{J}_{\mathrm{C}}$ increases as the total cross-sectional area increases.

The comments of Mark. Twain, recalled earlier, are probably even more applicable to measurements made on $\mathrm{Nb}_{3} \mathrm{Sn}$. Resistive voltages are more common in resistive transition plots, both because of the longer current transfer lengths in the resistive bronze and because of damage to the filaments. Both effects lead to broadened transitions, making the criterion used to define $J_{C}$ important. The strain sensitivity of $J_{C}$ can also lead to misleading results and it has also been shown that the form on which the wire is mounted can exert a significant influence on the $\mathrm{J}_{c}[75]$. The long barrel sample reacted and soldered to a stainless steel cylinder probably remains the most desirable test but it is also demanding in terms of the diameter of reaction furnace, ease of mounting and time required for test[76]. Since many reaction treatments are generally required to map out the characteristics of a composite, there is a tendency to accept simpler sample configurations yielding more questionable data. 
Suenaga $[10,11]$ has recent1y made an extensive summary of the $\mathrm{J}_{C}$ values found in the 1 iterature, both for conventional $\mathrm{FM} \mathrm{Nb}_{3} \mathrm{Sn}$ and its in situ variants. The results are shown in Figs. 25 and 26 .

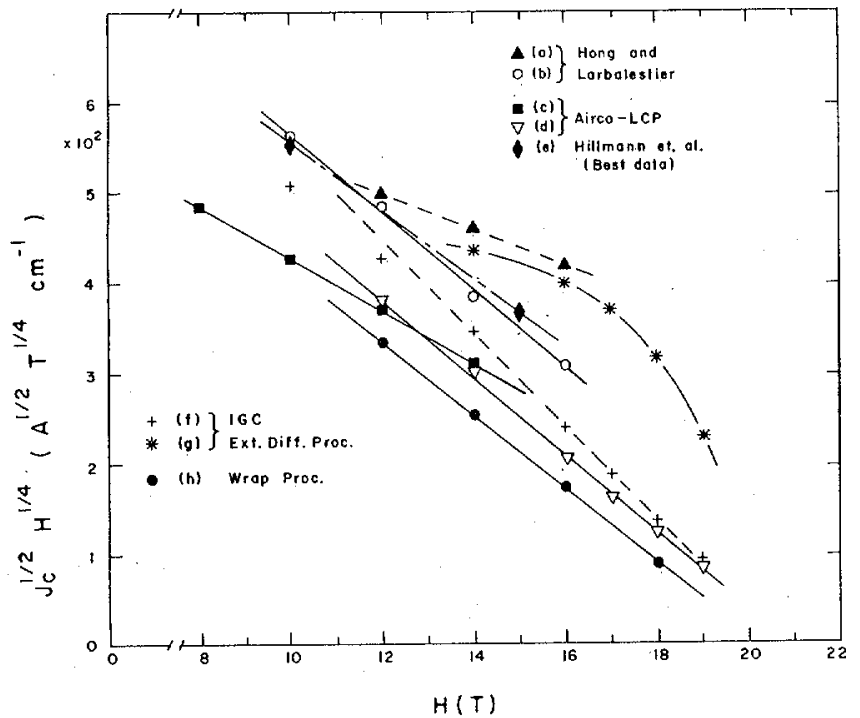

Fig. 25. A comparison of $J_{C}$ in commercially processed multifilamentary wires plotting $\mathrm{J}_{\mathrm{C}} 1 / 2 \mathrm{H} l / 4$
vs $H$.

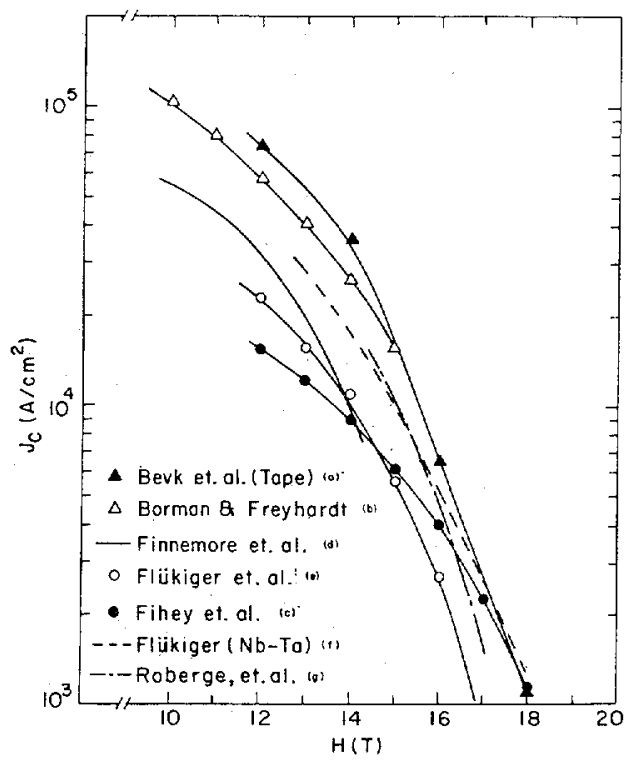

Fig. 26. A comparison of $J_{c}$ vs. H in experimental $\mathrm{Nb}_{3} \mathrm{Sn}$ wires produced by various in situ processes [17].

The diversity of values is obvious. It is also interesting to note that in situ ${ }_{\mathrm{C}}$ values, at least below about 12 Tesla, appear to be fully comparable to bronze route values.

The question of optimization through correct choice of composite design, filament size and reaction treatment remains largely unanswered. Perhaps the best characterized commercial composite remains the origina? AERE design $[55,59,76]$. The $J_{C}$ values of this composite were particularly good below about 14 Tesla (Fig. 27), falling off above this field due to the reduced $\mathrm{H}_{\mathrm{C}}$ produced by the high bronze to $\mathrm{Nb}$ ratio (4.6:1). Comparison to the properties of 2 lower ratio composites $(2.7: 1$ and $3: 1)$ appears to suggest a cross-over at around 14 Tesla, the lowest ratio composite being best at high fields, as expected from its lower precompression. More surprising is its lower J.c at lower fields - unless this may be related to the varying extent of the cubic to tetragonal phase transformation with varying bronze to $\mathrm{Nb}$ ratio. However, these comparisons must remain provisional since the 3 composites came from different manufacturers, had somewhat different fabrication histories, starting bronzes, etc. and are in no sense the product of a controlled production series. A11 the full line values are for 6 to 8 m diameter filaments, while the dashed line is for a nominally identical remake of the initial AERE composite with 3um dia. filaments[77].

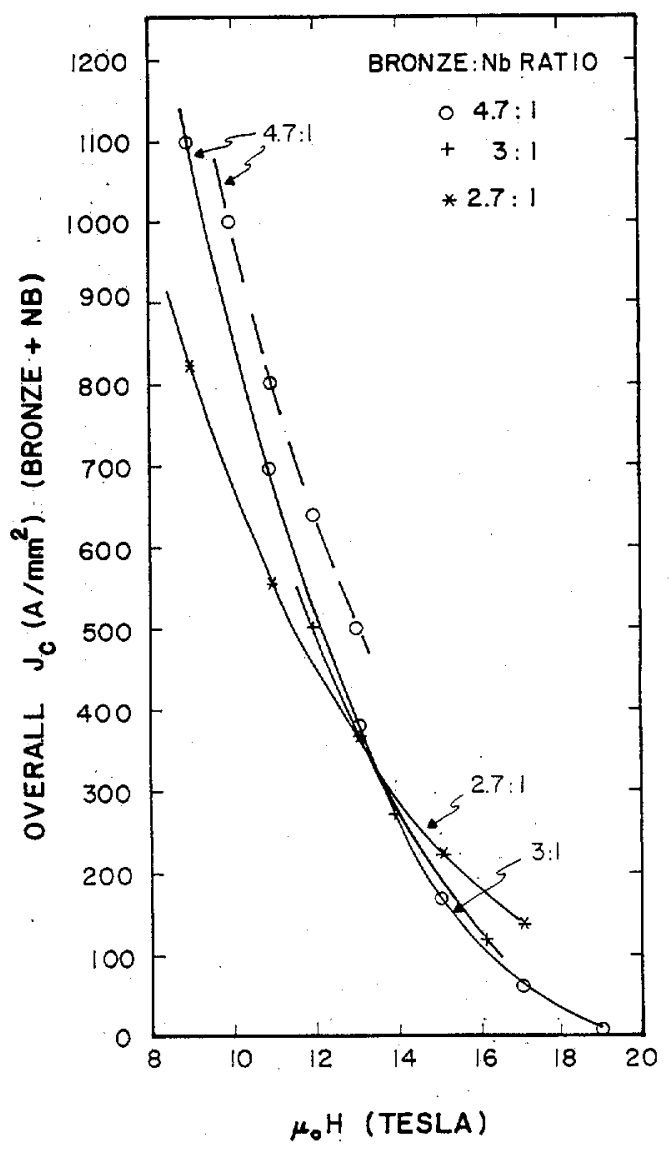

Fig. 27. J $J_{C}$ vs $\mu_{0} H$ for several $\mathrm{Nb}_{3} S n$ composites of different bronze to $\mathrm{Nb}$ ratios[77].

The absolute values of the $J_{C}$ are comparatively good, reaching $\sim 850 \mathrm{~A} / \mathrm{mm}^{2}$ at $10 \mathrm{~T}$ (higher in finer filaments, a trend confirmed elsewhere[78]) and 550 
$\mathrm{A} / \mathrm{mm}^{2}$ at $12 \mathrm{~T}$. An interesting conclusion to be drawn from a study of this composite is that there may be. some economic, as well as technical gain, to be derived from the higher bronze to $\mathrm{Nb}$ ratio composites, since bronze is appreciably cheaper than $\mathrm{Nb}$.

A final emphasis with respect to the question of $\mathrm{J}_{\mathrm{C}}$ in $\mathrm{FM} \mathrm{Nb}{ }_{3} \mathrm{Sn}$ is that we are still very uncertain about what a reasonable limiting value of $J_{c}$ should be and that there remains much that is curious about the reaction characteristics of particular composites. It is to be hoped that, as standard designs of composite become more widely available, as much effort will be put into their characterization as goes into their fabrication.

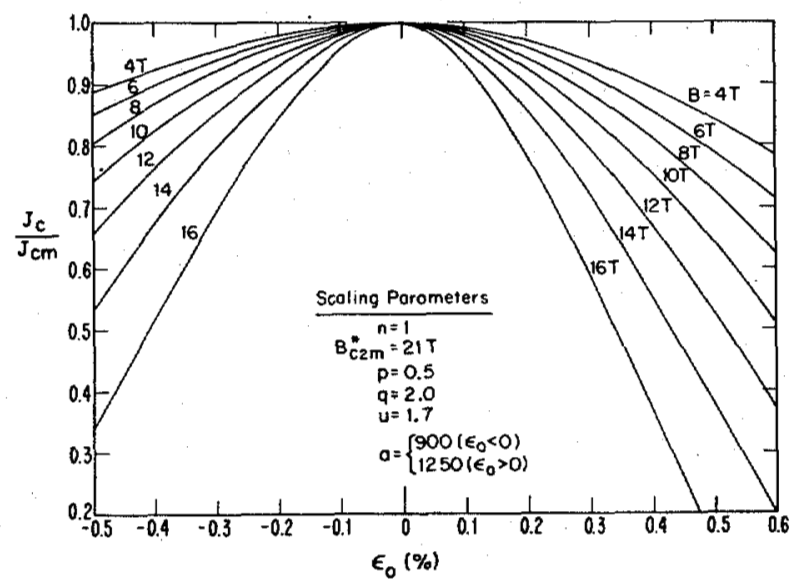

Fig. 28. Relative critical-current density $J_{c} / J_{c m}$ as a function of intrinsic strain $\varepsilon_{0}\left(\equiv \varepsilon-\varepsilon_{m i}\right)$. for different magnetic fields evaluated using Eq. (3) and the typical set of scaling parameters indicated in the figure [79].

\section{Strain Effects}

The strain sensitivity of $\mathrm{Nb}_{3} \mathrm{Sn}$ is of such fundamental importance to its application that a large amount of work has been performed and, as may be seen from the recent reviews of Welch[13] and Ekin[14], the subject appears to be phenomenonologicality well understood. Unless the bronze to $\mathrm{Nb}$ ratio is very low[58], uniaxial tensile strain is found to increase $\mathrm{T}_{\mathrm{C}}, \mathrm{H}_{\mathrm{C} 2}$, and $\mathrm{J}_{\mathrm{C}}$, until the point at which the residual axial strain on the $\mathrm{Nb}_{3} \mathrm{Sn}$ reaches zero. For practical composites, this requires strains of 0.3 to $0.6 \%$. The magnitude of the increase in $J_{c}$ is dependent on field and precompression, increasing with both parameters. Ekin[79] and Rupp[80], in particular, have stressed the utility of strain scaling, finding that data on a wide variety of commercial composites can be fitted to the equation[79]:

$$
\frac{J_{c}}{J_{c m}}=\left[\frac{{ }_{C_{2}}(\varepsilon)}{H_{C_{2 m}}}\right]^{n-p}\left[\frac{1-H / H_{c_{2}}(\varepsilon)}{1-H / H}\right]_{c_{2 m}}^{q}
$$

where the subscript $m$ refers to the maximum value obtained at zero intrinsic strain, while $n, p$ and $q$ are empirically determined exponents of values $\sim 1$, $\sim 0.5$ and 2, respectively. The utility of such a set of scaling relations is obvious and an example is shown in Fig. 28.

The preceding scaling behavior describes the elastic behavior of the $\mathrm{Nb}_{3} \mathrm{Sn}$ and ceases to be valid when filament cracking occurs. An interesting feature

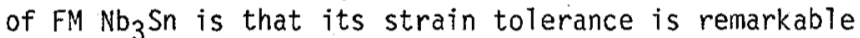
for a brittle material, since by the conventional rule of thumb, the $\mathrm{Nb}_{3} \mathrm{Sn}$ should fracture at a strain of $0.2 \%$ or less. The strain tolerance arises both from the precompression (the $\mathrm{Nb}_{3} \mathrm{Sn}$ must of course be taken into tension before it can crack) and the filamentary nature of the phase. Simple elastic stress analysis shows that the stress concentration at the root of a notch has the value $2(c / p)^{1 / 2}$, where $c$ is the crack half length and $\rho$ the radius of curvature at the notch root. $\rho$ is fixed, being of the order of the interatomic spacing in a brittle material, leaving the crack length as the important variable. Notches must be expected in brttle materials (see, for example, the irregular reaction in Fig. 22) and without plastic flow to blunt the notch, some cracking must always be expected. The upper limit to the crack length is clearly the fiber diameter. For a 1 um diameter filament, the stress concentration is about 45, rising to 1400 for a $1 \mathrm{~mm}$ dia. filament. Fine filaments thus have higher failure stresses (and strains) and the improved behavior of even finer filaments is confirmed in the in situ and special fine filament cu$\mathrm{Nb}$ composites $[17,81]$, where failure strains as high as 1 to $2 \%$ have been observed.

Although most experiments have been performed in uniaxial tension, the case of bending is also important. Luhman et a].[82] have shown that the bend tolerance is not as high as the uniaxial strain tolerance. The reason for this is that the bronze on the outer tension side of the neutral axis yields before that on the inner circumference, forcing the neutral axis towards the center of curvature and preferentially damaging the outer filaments. However, for bath types of stress, the fracture is progressive rather than catastrophic and bend strains of $\sim 0.5 \%$ appear feasible in practical conductors.

As a practical point, we may note that the first coils to be wound of $\mathrm{FM} \mathrm{Nb}_{3} \mathrm{Sn}$ performed very well at stresses of up to $150 \mathrm{MPa}[59]$. Their quench currents were substantially (35 to $50 \%$ ) greater than the short sample critical currents but since these were obtained in the early 1970's when training was expected to reduce the behavior of the magnets the results seemed improbable and were not published until some 3 years later[59]. In fact, the earliest experiments on the tensile properties of individual wires proved that it was easier to damage the wires in isolation than was the case when they were wound into coils, and reacted in place. The prospects for magnet use are therefore very good. Since the maximum peak design strain seldom exceeds $0.2 \%$ in a large magnet, $\mathrm{Nb}_{3} \mathrm{Sn}$ has in principle a safety margin of 2 to 3 in strain. The problem of utilizing the $\mathrm{Nb}_{3} \mathrm{Sn}$ is thus a problem of ensuring that this strain will not be exceeded or of 
providing appropriate relief (extra cooling etc.) for regions where it may be.

Fabrication Considerations

Although the usage of $\mathrm{FM} \mathrm{N}_{3} \mathrm{Sn}$ does not yet approach that of $\mathrm{Nb}-\mathrm{Ti}$, there is now a considerable forward committment to its use in large magnets and large scale production lines have been set up to produce it. We have already remarked on the large diversity of present conductor designs and the extent, therefore, to which any one design can be considered standard is doubtful. The design to be most widely produced in the near future is, however, the LCP strand at Airco (Fig. 29). Over 100 extrusions of this design will be made and much will be learnt about the effect of process variables if good characterizations are made of different billets of this conductor[83].

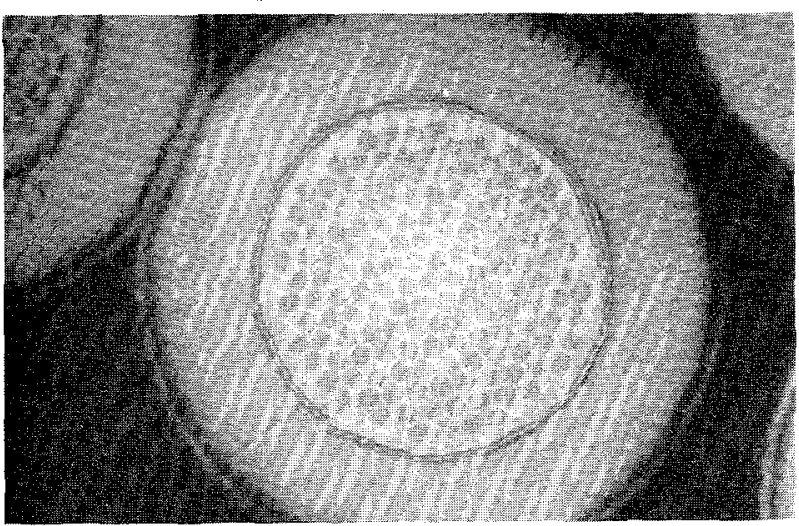

Fig. 29. The Airco LCP conductor. (Courtesy of P. Sanger)

Alternative processing routes of a variety of designs have been proposed and wire produced on a small scale. Amongst these we may cite the external diffusion route, applied both to conventionally stacked $\mathrm{Cu}-\mathrm{Nb}$ billets and in-situ billets, the use of sn-rich compounds in place of bronze as the Sn source and the extensive work on in-situ composites, using both casting and powder extrusion routes. We refer to recent reviews $[10,11,15-17]$ for more details of these processes. This diversity of approach emphasizes that $\mathrm{Nb}_{3} \mathrm{Sn}$ of good quality can be produced in a variety of ways, even if none of these alternative processes has yet achieved commercialization.

Atthough cost advantages are frequently cited in support of alternative routes to $\mathrm{FM} \mathrm{Nb}_{3} \mathrm{Sn}$, it should be realized that these arguments really rest on a very uncertain foundation. The reason for this is that we do not yet have firm cost data (that is published at least) for bronze route $\mathrm{Nb}_{3} \mathrm{Sn}$. A start might, however, be made by dividing the costs into raw material and fabrication categories. Since the raw material costs tend to be similar from process to process, this may indicate whether much is to be gained from alternative processing. The data in Tables 4 and 5 enable such a comparison to be made for $\mathrm{Nb}-\mathrm{T} \mathrm{j}$ but I am not aware of any comparable data for $\mathrm{Nb}_{3} \mathrm{Sn}$.

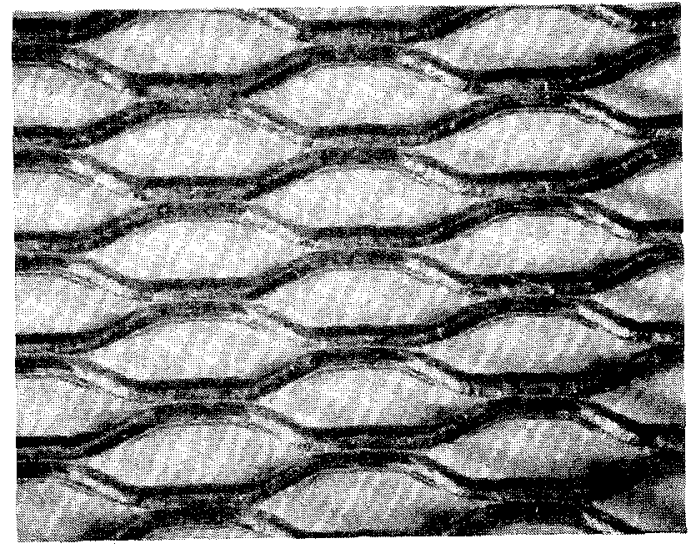

Fig. 30. Expanded $\mathrm{Nb}$ sheet used in the Jelly Roll $\mathrm{Nb}_{3} \mathrm{Sn}$ composite shown in Fig. 31. (Courtesy of W.K.McDonald.)

One variant of the bronze process recently proposed by Wah Chang does however deserve sone mention in view of its interesting properties and apparent production simplicity. $\mathrm{Nb}$ foil is slit on a conventional slitter used to produce expanded mesh (Fig. 30) and rolled in a "jelly or Swiss roll". with bronze sheet, so as to produce a multiply connected filament network. After wrapping with a diffusion barrier and a Cu stabilizer, the billet is compacted and then extruded and drawn in a conventional manner[84]. Recent reports of the AC loss of this composite (Fig. 31) suggest that it acts much more like a conventionally stacked composite with disconnected filaments than a multiply connected in situ composite[85]. The prospects for this Wah chang process may be considerable, therefore, in view of the elimination of much billet stacking and multiple extrusion work.

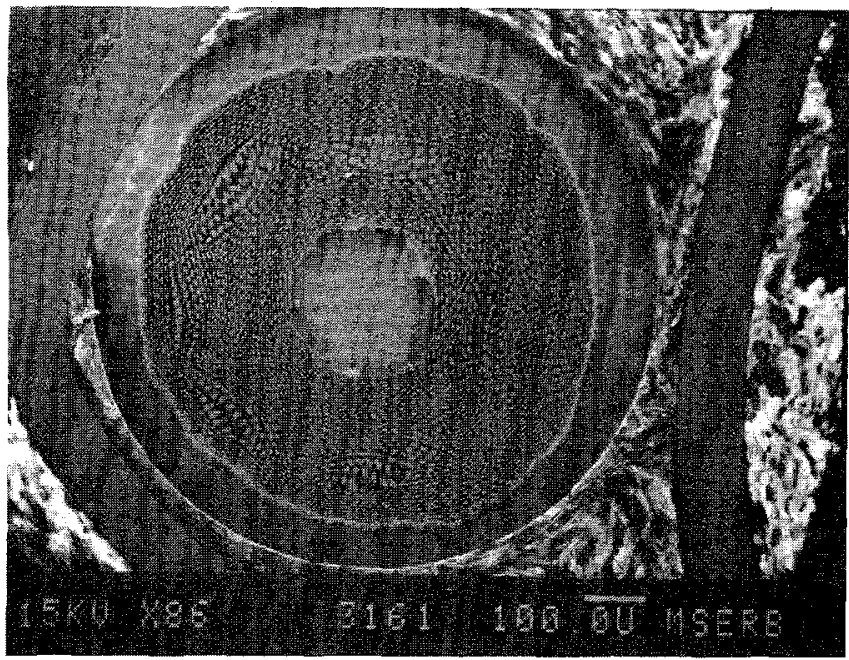

Fig. 31. The Jelly Roll $\mathrm{Nb}_{3} \mathrm{Sn}$ composite of Wah Chang. (Courtesy of W.K. MCDonald.) 


\section{ACKNOWLEOGEMENTS}

A number of people deserve my thanks for help in the preparation of this review. I am particularly indebted to members of my own group for discussions and assistance; particularly David G. Hawksworth, David B. Smathers and David L. Moffat. The use of unpublished thesis work of David G. Hawksworth and David B. Smathers is also gratefully acknowledged. Recent discussions with Dr. Masaki Suenaga on the properties of $\mathrm{Nb}_{3} \mathrm{Sn}$ were al so of great assistance.

Finally I am pleased to acknowledge the support for our research provided by the Department of Energy, Office of Fusion Energy and Energy Storage Systems.

\section{REFERENCES}

1. Workshop Panel Session, "Superconductors for Magnets: Frontiers of Technology," Session. WA-1, this conference.

2. D.B. Montgomery, Proceedings of the 6 th Symposium on Eng. Problems of Fusion Research, IEEE Publication 75CH1097-5-NPS, p. 122 (1975).

3. M.A. Green, paper DD-1, this conference.

4. Advances in Cryogenic Engineering 26 10, Plenum Press (1981).

5. Filamentary A15 Superconductors, editors M. Suenaga and A.F. Clark, Plenum Press (1980).

6. Superconducting Materials, editors S. Foner and B.B. Schwartz, Plenum Press (1981).

7. Proceedings of the $1980 \mathrm{Appl}$ ied Superconductivity Conference, IEEE Trans. MAG. 171 (1981).

8. D.C. Larbalestier, Ref. 4.

9. D.C. Larbalestier, Ref. 6.

10. M. Suenaga, Ref. 6.

11. M. Suenaga, Ref. 7.

12. H. Hillmann, Ref. 6 .

13. D.0. Welch, Ref. 4 .

14. J.W. Ekin, Ref. 6 .

15. D.K. Finnemore, Ref. 4.

16. S. Foner, Proceedings of the 8th Symposium on Engineering Problems of Fusion Research, IEEE Publication 79CH1441-5-NPS, p. 230 (1979).

17. R. Roberge, Ref. 6.

18. J. Bevk, M. Tinkham, F. Habbal, C.J. Lobb and J.P. Harbison, Ref. 7, p. 235.

19. A.I. Braginski and G.R. Wagner, Ref. 7, p. 243.

20. R. Flukiger, Ref. 6 .

21. A.W. West, University of Wisconsin, unpublished.

22. A.W. West and R.D. Rawlings, J. Mat. SCi. 12, 1862 (1977).

23. J.E. Evetts, J.R. Cave, R.E. Somekh, J.P. Stanton and A.M. Campbel1, Ref. 7 p. 360.

24. D.B. Smathers and D.C. Larbalestier, Ref. 4, p. 415.

25. D.B. Smathers and D.C. Larbalestier, Ref. 5, p. 143.

26. D.G. Hawksworth and D.C. Larbalestier, Ref. 16, p. 249 .

27. E.J. Kramer, J. Appl. Phys. 44, 1360 (1973).

28. D.G. Hawksworth, Ph.D. thesis, University of Wiscons in (1981).

29. N.E. Al ekseevski, 0. Ivanov, I.I. Rayevskij and N.V. Stepanov, Sovjet Physics Doklady 12,9 (1968).

30. T. Horiuchi, Y. Monju and N. Nagai, J. Jap. Inst. Met. 37, 8.883 (1973).

31. D.G. Hawksworth and D.C. Larbalestier, to be published.

32. N.R. Werthamer, E. Helfand and P.C. Hohenberg, Phys. Rev. 147, 295 (1967).

33. T.P. Orlando, E.J. McNiff, Jr., S. Foner and M.R. Beasley, Phys. Rev. B19 4545 (1979).
34. J.S. Alcorn, J.R. Purcell, W.Y. Chen and Y.H. Hsu, Ref. 7 p. 642.

35. I. Pfeiffer and H. Hillmann, Acta Met. 161429 (1968).

36. D.F. Neal, A.C. Barber, A. Woolcock and J.A.F. Gidley, Acta Met 19143 (1971).

37. P.R. Critchlow, E. Gregory and B. Zeitlin, Cryogenics 113 (1971).

38. A.W. West and D.C. Larbalestier, Ref. 4.

39. A.W. West and D.C. Larbalestier, Ref. 7, p. 65.

40. H. Hillmann, Int. Disc. Meeting on Flux Pinning in Superconductors, Sonnenberg, W. Germany (1974) p. 235.

41. Oxford Dictionary of Quotations, Oxford University Press (1979) p. 187.

42. A.S.T.M. committee, F. Fickett, NBS Boulder, CO, private communication.

43. K.F. Hwang and D.C. Larbalestier, IEEE Trans. Mag. 15,1 p. 400 (1979).

44. W.A. Fietz and W.W. Webb, Phys. Rev. 178 p. 657 (1969).

45. D.G. Hawksworth and D.C. Larbalestier, Ref. 7 p. 49 .

46. E.J. Kramer, J. Electronic Mat7s. 4, 839 (1975).

47. R.G. Hampshire and M.T. Taylor, J.Phys. F 2, 89 (1972).

48. H.R. Segal, T. M. Hrycarj, Z.J.J. Stekley, T.A. dewinter and K. Hemachalem, Ref. 16, p. 274.

49. H.R. Segal, Z.J.J. Stekley, T.A. dewinter and K. Hemachalem, paper BB-10, this conference.

50. R.H. Remsbottom, University of Wisconsin, private communication.

51. B.A. Zeitlin, Intermagnetics General Corporation, private communication.

52. R.J. Marsh and W.K. McDonald, Teledyne Wah Chang, private communication.

53. C.W. Curtis and W.K. McDonald, IEEE Trans. MAG. 13, 769 (1977).

54. E. Gregory, E. Adam, S. Hong, W. Marancik. P. Sanger, C. Spencer, paper FB-1, this conference.

55. D.C. Larbalestier, P.E. Madsen, J.A. Lee, M.N. Wilson and J.P. Charlesworth, IEEE Trans. MAG 11, 247 (1975)

56. E. Gregory, W.G. Marancik and F.T. Ormand, IEEE Trans. MAG 11, 295 (1975).

57. D.C. Labalestier, IEEE Trans MAG 15, 209 (1979).

58. D.C. Larbalestier, J.E. Magraw and M.N. Wilson, IEEE Trans. MAG 13, 462 (1977).

59. D.C. Larbalestier, Proc. MT-6, Alfa Pub1. Co., Bratislava 1080 (1978).

60. J.A. Lee and C.A. Scott, ibid, p. 35, Ref. 5 .

61. P.A. Sanger, E. Adam, E. Ioriatti and S. Richards, Ref. 7, p. 666 .

62. R. Scantan, Lawrence Livermore National Lab, private communication.

63. V.M. Horrigan, Met. Trans A 8A, 785 (1977).

64. M. Suenaga and D.0. Welch, Ref. 5, p. 131 .

65. D.B. Smathers, unpublished work.

66. T.P. Orlando, J.A. Alexander, S.J. Bending, J. Kwo, S.J. Poor, R.H. Hammond, M.R. Beasley, E.J. McNiff, Jr.; and S. Foner, Ref. 7, p. 368.

67. H. Devantay, J.L. Jorda, M. DeCroux, J. Muller and R. Flukiger to appear in J. Mat. Sci.

68. R.W. Hoard, R.M. SCanlan, G.S. Smith and C.L. Farrell, Ref. 7, p. 364. 3140

69. R. Flukiger, Report KFK Oct.1980, Kernforschungszentrum Karlsruhe

70. D.M. Kroeger, D.S. Easton, C.C. Koch and A. DasGupta, Ref. 5, p. 205.

71. R. Roberge, H. LeHuy, S. Foner, to appear in Phys. Lett.

72. R. Flukiger, W. Specking, B. Schmidt and E. Springer, paper $\mathrm{GB}-6$, this conference.

73. S. Foner and E.J. McNiff, Jr., Appl. Phys. Letts. $32,122(1978)$. 
74. H. Sekine and K. Tachikawa, Appl. Phys. Letts. 35, 472 (1979).

75. H. Hillman, H. Pfister, E. Springer, M. Wilhelm and $K$. Wohlleben, Ref., p. 17.

76. S.0. Hong and D.C. Larbalestier, IEEE Trans MAG 15,784 (1979).

77. S.0. Hong and D.C. Larbalestier, unpublished work.

78. M.S. Walker, J.M. Cutro, B.A. ZeitTin, G.M. Ozeryansky, R.E. Schwali, C.E. OberTy, J.C. Ho and J.A. Wooll am, IEEE Trans MAG 1580 (1979).

79. J.W. Ekin, Ref. 7, p. 658.

80. G. Rupp, Ref. 7, p. 1099.

81. S.F. Cogan, D.S. Holmes, R.M. Rose, J. App1. Phys. $514332(1980)$.

82. T. Luhman, D.0. Welch, M. Suenaga, Ref. 7, p. 662.

83. P. Sanger, Airco, private communication.

84. W.K. McDonald, Wah Chang, private communication.

85. S.S. Shen, Oak Ridge National Lab, private communication. 